\title{
Recent Developments on the Use of Polymers as Corrosion Inhibitors - A Review
}

\author{
S.A. Umoren ${ }^{*}$ and M.M. Solomon
}

\author{
Materials and Corrosion Protection Research Laboratory, Department of Chemistry, Faculty of Science, University of \\ Uyo, Uyo, Nigeria
}

\begin{abstract}
The use of corrosion inhibitors is the one the most economical and practical means of controlling metallic corrosion in different corrosive media. Interest on the use of eco-friendly organic compounds as corrosion inhibitors has extended to the use of polymers to inhibit metallic corrosion. The use of polymers as corrosion inhibitors has attracted attention and has gained wide acceptance in recent times. This has been attributed to a number of factors namely: (i) they are low cost and stable to metallic materials in acid media, (ii) they possess multiple adsorption sites, (iii) through their functional groups, they form complexes with metal ions and on the metal surface these complexes occupy a large area, thereby blanketing the surface and protecting the metal from corrosive agents present in the solution. A number of synthetic and natural polymers as metallic corrosion inhibitors have been investigated and reported. As an update to previous review work on the use of polymers as corrosion inhibitors, the present review presents most of the contributions made to the literature on the use of polymers as corrosion inhibitors of diverse metals in different corrosive media in the last four (2010-2013) years.
\end{abstract}

Keywords: Aluminum, corrosion inhibition, polymers, steel.

\section{INTRODUCTION}

Metals have continued to be a choice raw material in areas such as structural, fabrication, electrical and electrochemical, hot-dip galvanizing, etc. This usage stem from the many interesting properties of metals which include: high melting and boiling points; characteristic lustre; malleability; ductility; hardness with great tensile strength; relatively high densities; and good conductivity. Unfortunately, these properties deteriorate when metals interact with certain elements that recur within their environments; a process which is technically called corrosion. The rate and extent to which metal corrode depend on two broad factors: the nature of the metal and the nature of the corroding environment. The nature of the metal encompasses the position of the metal in galvanic series (metals in the active zone of the galvanic series corrode faster than those in the noble zone), overvoltage (reduction in overvoltage of the corroding metal promotes corrosion process), relative areas of anodic and cathodic parts (when two dissimilar metals are in contact, the corrosion of the anodic part varies as the ratio of the area of cathodic part), purity of metal (impurities present in a metal give rise to heterogeneous state which form minute electrochemical cell and as a consequence, corrosion of the anodic part is accelerated), physical state of the metal (grain size, stress orientation of crystals, etc. affect corrosion rate), nature of surface film (the specific volume ratio which is the ratio of

*Address correspondence to this author at the Materials and Corrosion Protection Research Laboratory, Department of Chemistry, Faculty of Science, University of Uyo, Uyo, Nigeria; Tel: +2348094208559 ;

E-mail: saviourumoren@yahoo.com volume of metal oxide to the metal has direct influence on corrosion rate. If the specific volume ratio is low, corrosion rate will be high), passivity of metal (passive metals are resistant to corrosion), solubility of corrosion products (if the corrosion product is soluble in its medium then corrosion of the metal will be accelerated) and volatility of corrosion product. Similarly, temperature (varies directly with corrosion rate), moisture (more moisture, high rate of corrosion), $\mathrm{pH}$ value (lesser the $\mathrm{pH}$ i.e. acidic conditions, more is corrosion), and the nature of electrolyte (presence of salts in the electrolyte increases the rate of corrosion) defined the nature of the corroding environment. Also, certain industrial practices like acid pickling, acid cleaning of boilers, decaling, etc. accelerate metal corrosion process. The devastating effects of corrosion are enormous and these include: hazards to people due to structural failure (e.g. bridges, cars, aircrafts etc.); value depreciation of metals as a result of deterioration of appearance; loss of important surface properties of a metallic component; perforation of vessel and pipes allowing escape of their contents and possible pollution of the environments; mechanical damage to valves, pumps, etc, or blockage of pipes by solid corrosion products. Consequently, nations' economies have been greatly drained. Several approaches have been adopted toward reducing or at best preventing corrosion. These include the use of protective coatings (painting, electroplating, and greasing), design of hydraulic systems to avoid excessive velocities or localized turbulence, removal of oxygen, if present, with oxygen scavengers and adjustment of the $\mathrm{pH}$ to levels above 10, among others [1]. While these approaches work in many aqueous environments, they are not practical for many production fluids, and the use of corrosion inhibitors - chemicals added 
to the corrosive environment in small concentrations to reduce the rate of corrosion, will often become necessary. These corrosion inhibitors will, in many cases, reduce the corrosion rate to approximately $5-10 \%$ of the corrosion rate with no inhibitors. However, it is not all substances that are suitable as metal corrosion inhibitor. The following are the basic requirements: (i) it should easily oxidize the metal surface to form an impervious and compact film (ii) it should have highly disposable site (s) from which it could be chemisorb onto the metal surface; (iii) the barrier film thus formed should be able to blanket a large area of the metal surface; (iv) it should be polymeric or polymerize in situ on the surface of the metal; (v) it should be eco-friendly; (vi) it should be readily available, low cost, and safe in handling.

Corrosion inhibitors have been classified in many ways, but one of the most common is classification into groups, based on how they control corrosion [2] as follows:

- $\quad$ Adsorption or film - forming inhibitors;

- $\quad$ Precipitation inhibitors;

- Oxidizing or anodic passivation inhibitors;

- $\quad$ Cathodic corrosion inhibitors;

- $\quad$ Environmental conditioners or scavengers;

- Volatile or vapor - phase inhibitors.

These groupings and others are shown in Fig. (1) [3]. Another possible classification is into organic and inorganic inhibitors. Most corrosion inhibitors used for oilfield applications are film - forming organic chemicals, but commercial multi-component inhibitor packages often contain inorganic oxygen, $\mathrm{H}_{2} \mathrm{~S}$ scavengers and oxidizing agents in addition to the film - forming organic components. Inhibitors do their work at low relative dosages (often expressed in parts per million or quarts per 1000 barrels). Most oilfield inhibitors work by forming hydrophobic films on metal surfaces.

There are serious concerns on the suitability of inorganic and organic compounds as metal corrosion inhibitors. For instance, chromium compounds were widely used as effective metal corrosion inhibitors in aqueous systems [4-6] but has been found to exhibit high toxicity and consequently prohibited to use for industrial applications [7]. Alternatively, lanthanide salts were advocated to show excellent inhibition properties [8,9], which could replace chromates, unfortunately, lanthanide salts like lanthanide chlorides have been reported to possess toxicity that is comparable with sodium chloride [10]. The organic corrosion inhibitors, although receiving considerable attention because of their high solubility in aqueous corrosive environments, ease of adsorption on the metal surface, stability of the adsorbed film, and effectiveness of the adsorbed film against aggressive ions present in the medium of which they are use [11-13], the tedious synthetic procedures and the exorbitant prices of most organic corrosion inhibitors have come under severe criticisms.

The search for a perfect replacement of inorganic and organic metal corrosion inhibitors has long begun and attention seems to be geared towards polymeric (naturally occurring and synthetic) materials. Polymers are substances composed of molecules characterized by multiple repetitions of one or more species of atoms or group of atoms linked to each other in amount sufficient to provide a set of properties. Interest in polymers is principally due to its availability, cost effectiveness, and eco-friendliness in addition to the inherent stability and multiple adsorption centers [14]. We have reported the use of polyacrylamide as inhibitor for aluminum in $\mathrm{HCl}$ solution [15], carboxymethyl cellulose for mild steel in sulphuric acid medium [16] and detailed information on the utilization of polymers as metal corrosion inhibitors in different corrosion inducing environments can be found in our earlier review [17] and in that of Kalaivani et al. [18]. Nevertheless, most polymeric materials are not readily soluble in aqueous medium and this always have negative influence on the inhibition efficiency of polymers. Several modifications have been done in recent days in an attempt to enhancing the effectiveness of polymers as metal corrosion inhibitors. Gupta and Singh [19] showed that mixed poly ( $\mathrm{N}$ hexadecylaniline)/docosanol films were more stable on copper surface and thus exhibited better inhibitive effect on the corrosion of copper in sea water than pure poly $(\mathrm{N}$ -

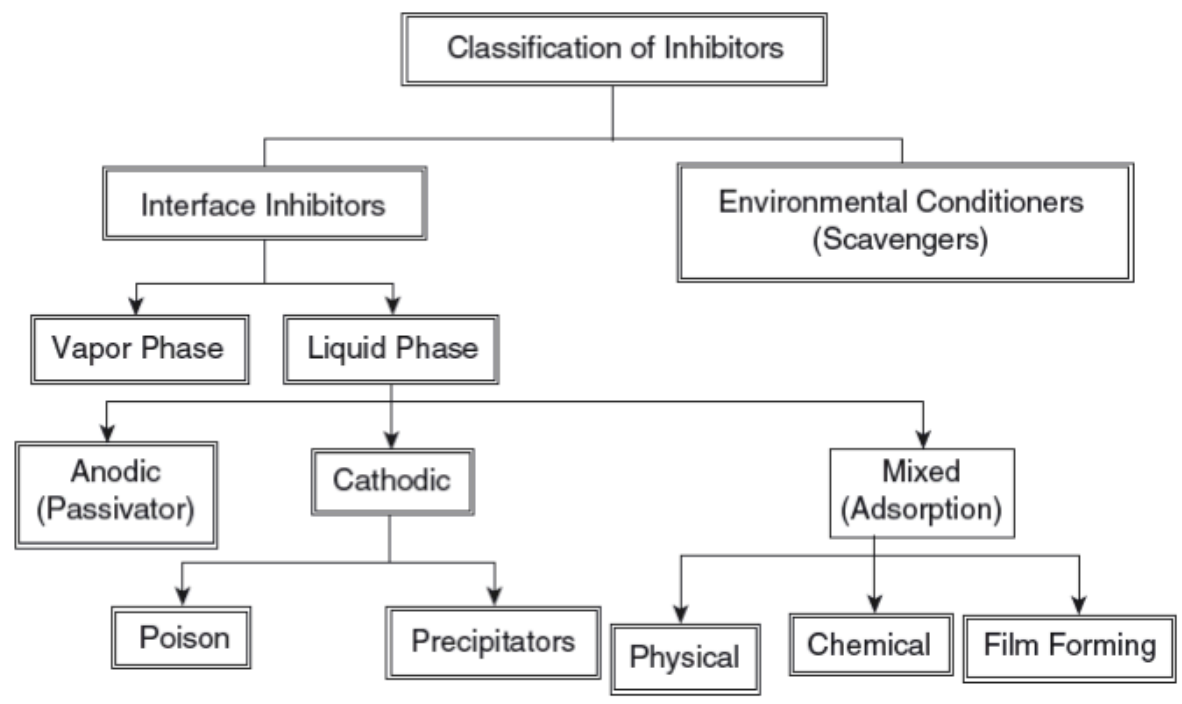

Fig. (1). Corrosion inhibitors classification [3]. 
hexadecylaniline). Benabdellah et al. [20] in their investigation on the inhibiting abilities of two copolymers namely, poly (vinyl caprolactone-co- vinyl pyridine) and poly (vinyl imidazol-co-vinyl pridine) on the corrosion behavior of steel in phosphoric acid at different temperatures, concluded that these copolymers have excellent inhibitive effects. Similarly, additions of halides to polymers have been reported to significantly modify the inhibitive efficiency of polymers [21-23].

This article therefore focuses on recent reports on the utilization of polymers as metal corrosion inhibitors and the modification done to improve upon the inhibiting forces of polymers in different corrosion inducing environments. Also, the recent development of application of quantum chemical calculations and molecular dynamic simulations to understand the interactions of polymers used as corrosion and metal substrates have been highlighted.

\section{NATURALLY OCCURRING POLYMERS AS METAL CORROSION INHIBITORS}

A number of naturally occurring polymers have shown promising results as metal corrosion inhibitors in different corrosive environments. The structures of some recently studied natural polymers as metal corrosion inhibitors are given in Table 1. The inhibiting effect of naturally occurring pectin polymer on aluminum corrosion in acidic media has been investigated and reported [24]. The result obtained shows that the inhibition efficiency of pectin first increased linearly and then exponentially with concentration until a plateau was reached. Temperature was found to have profound effect on the inhibition efficiency; a severe decline from $91 \%$ at $10^{\circ} \mathrm{C}$ to $31 \%$ at $40^{\circ} \mathrm{C}$ with the same concentration of pectin was reported. Hassan and Zaafarany [25] studied the corrosion inhibition of aluminum (Al) in hydrochloric acid by anionic polyelectrolyte pectates as a

Table 1. Chemical structures of repeat units of some naturally occurring polymers used as corrosion inhibitors.

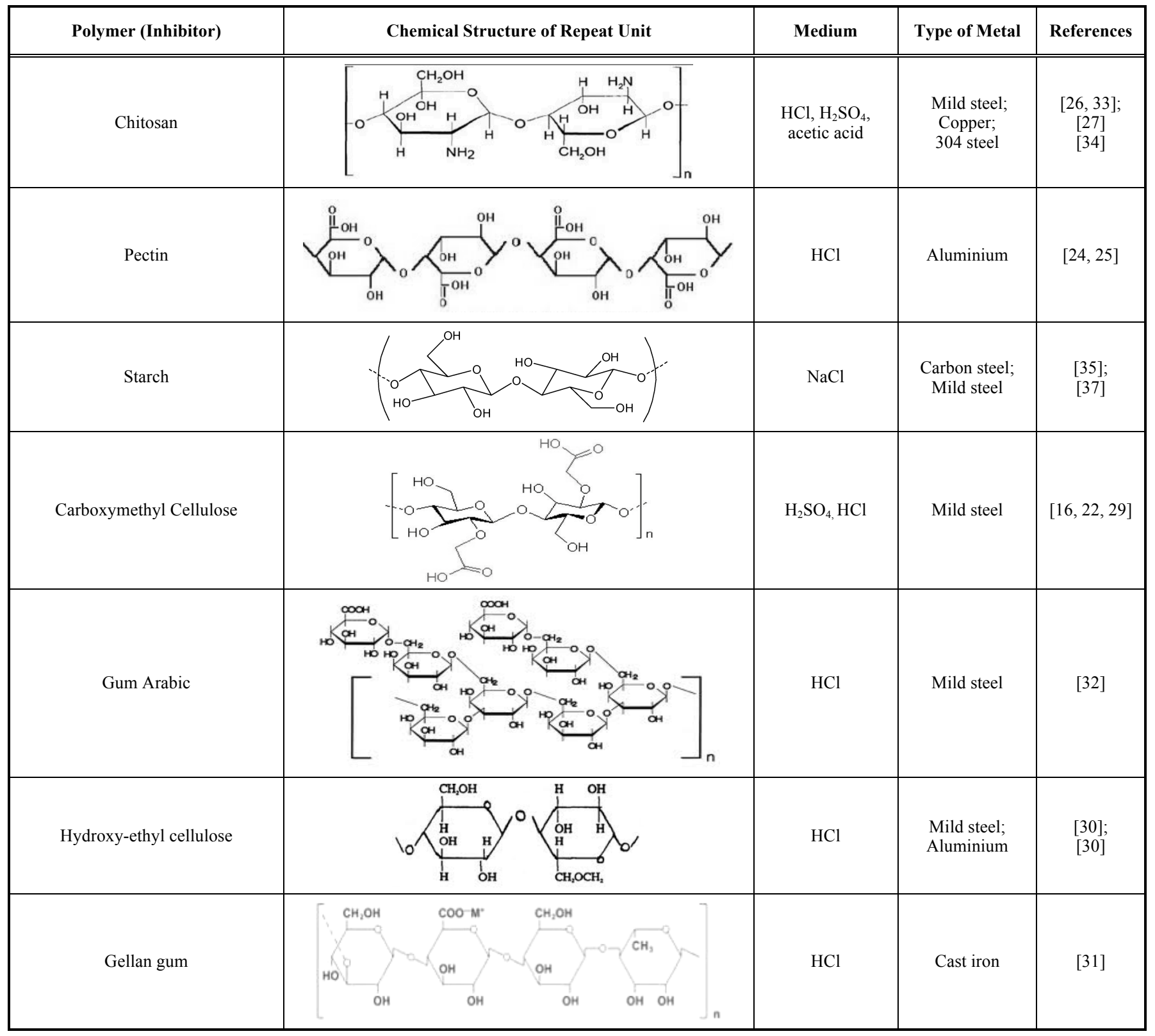


water-soluble natural polymer polysaccharide using gasometric and weight loss methods. Results of the investigation revealed that the inhibition efficiency offered by inhibitor increased with increase in the concentration but decreased with rise in temperature. The authors proposed that the geometrical configuration and functional groups within the inhibitor molecule were the main factors that influenced the inhibition efficiency.

The inhibitive influence of chitosan as a green corrosion inhibitor for mild steel in $0.1 \mathrm{M} \mathrm{HCl}$ was studied [26] using gravimetric, potentiodynamic polarization, electrochemical impedance spectroscopy, scanning electron microscopy, and UV-visible techniques. The polymer was found to moderately inhibit the corrosion of mild steel in the studied environment even at low concentration and had influence on both the anodic and cathodic reactions. 68.0\% inhibition efficiency was obtained with the highest concentration of the inhibitor used $(4 \mu \mathrm{M})$ from potentiodynamic measurements. El-Haddad [27] has reported that chitosan retard the dissolution of copper in $0.5 \mathrm{M} \mathrm{HCl}$ effectively. The investigation was carried out using weight loss, potentiodynamic polarization, electrochemical impedance spectroscopy (EIS) and electrochemical frequency modulation (EFM) measurements. It was found from potentiodynamic polarization measurements that the chitosan acts essentially as a mixed-type inhibitor. Results of EIS indicated that the value of constant phase elements (CPEs) tends to decrease and both charge transfer resistance and inhibition efficiency tend to increase by increasing the inhibitor concentration. The studied inhibitor was found to show good inhibition efficiency in $0.5 \mathrm{M} \mathrm{HCl}$. The adsorption of inhibitor on the copper surface was also seen to obey Langmuir adsorption isotherm. However, the author explained the mechanism of inhibition of copper corrosion in $\mathrm{HCl}$ by chitosan by considering the dissolution pattern of copper in acidic environment reported by Solmaz et al. [28]. According to Solmaz et al., the anodic dissolution of copper in $\mathrm{HCl}$ solution takes place in two continuous steps;

$\mathrm{Cu} \leftrightarrow \mathrm{Cu}_{\mathrm{ads}}^{+}+\mathrm{e}-$ (fast step)

$\mathrm{Cu}_{\mathrm{ads}}{ }^{+} \leftrightarrow \mathrm{Cu}^{2+}+\mathrm{e}-$ (slow)

where $\mathrm{Cu}_{\mathrm{ads}}{ }^{+}$is an adsorbed species at the copper surface. The reaction step (2) is generally the rate determining step and controlled by diffusion of soluble $\mathrm{Cu}^{2+}$ species from the electrode surface to the bulk solution. El-Haddad noted that the value of adsorption energy $\left(\Delta G_{a d s}\right)$ indicated that the adsorption of chitosan on the copper surface was more of chemical mechanism than physical one. Chemical adsorption of chitosan was taken to arise from the donor acceptor interactions between free electron pairs of heteroatoms and vacant d-orbitals of copper.

$\mathrm{Cu}+x \mathrm{Cs} \leftrightarrow \mathrm{Cu}-x \mathrm{Cs}_{\mathrm{ads}}$

where Cs is chitosan and $x$ is the number of Cs molecules adsorbs on the copper surface. The formation of a thin adsorbed layer reduced the corrosion rate of copper. Nevertheless, the author stated that the complexation of Cs molecules with $\mathrm{Cu}^{+}$species on the copper surface was possible;

$\mathrm{Cu}^{+}+\mathrm{xCs} \leftrightarrow[\mathrm{Cu}-\mathrm{Csx}]_{\mathrm{ads}}^{+}$
The product of $[\mathrm{Cu}-\mathrm{Csx}]_{\mathrm{ads}}{ }^{+}$chelate participate and form a protective film over the copper surface which provided a good protection against corrosion by a physical barrier effect. Meanwhile, the adsorption of organic molecules on a metal surface cannot be said to strictly follow physical or chemical adsorption mechanisms. These two mechanisms can prevail within the same system. Hence, ElHaddad in addition to the chemical adsorption mechanism proposed, stated that the inhibitor molecules can as well be adsorbed on the copper surface via electrostatic interaction between the charged metal surface and the charged inhibitor molecules if it is possible. From the value of the standard free energy of adsorption which was found to be modestly lower than $-40 \mathrm{~kJ} \mathrm{~mol}^{-1}$, El-Hadda concluded that there exist contributions from physical adsorption.

Solomon et al. [16] used weight loss, hydrogen evolution, and thermometric techniques to investigate the protective ability of carboxymethyl cellulose (CMC) on mild steel in sulphuric acid solution at $30-60{ }^{\circ} \mathrm{C}$. Results obtained showed that $\mathrm{CMC}$ act as inhibitor for mild steel in $\mathrm{H}_{2} \mathrm{SO}_{4}$ solution. The inhibition efficiency was found to increase with increase in CMC concentration but decreased with rise in temperature, which physical adsorption mechanism was proposed. The adsorption of the CMC onto the mild steel surface was found to follow Langmuir and DubininRadushkevich adsorption isotherm models. However, the authors compared the inhibition efficiency of CMC gotten in the work with that obtained by Bayol et al. [29] in $\mathrm{HCl}$ solutions and found that the inhibition efficiency of CMC in the work of Bayol et al. was higher which is a confirmation to the assertion that organic species exhibit higher inhibiting effect in chloride containing solutions than in sulphate containing solutions. Arukalam et al. [30] carried out a comparative study on the effect of hydroxyethyl cellulose (HEC) on mild steel and aluminum corrosion in $0.5 \mathrm{M} \mathrm{HCl}$ solution under atmospheric exposure using weight loss method. From the results obtained HEC was found to be a better inhibitor for mild steel than aluminum in $\mathrm{HCl}$ solutions.

Glucose, gellan gum, and hydroxylpropyl cellulose have been assessed as green inhibitors for cast iron in acidic environment by means of chemical and electrochemical techniques [31]. It was found that inhibition efficiency increased with increase in the concentration of the inhibitors. Also the protective effect of glucose and hydroxylpropyl cellulose decreased as the temperature was raised while the inhibition ability of the gellan gum increase gradually with rise in temperature. The polymers were seen to influence both the anodic and cathodic reactions and the mode of their adsorption on the cast iron followed Langmuir adsorption isotherm. Investigation into the inhibiting ability of Gum Arabic (GA) on the corrosion of API 5L X42 pipeline steel in $1 \mathrm{M} \mathrm{HCl}$ solution using electrochemical impedance spectroscopy and potentiodynamic polarization methods by Bentrah et al. [32] show that Gum Arabic could afford 92\% protection at $2 \mathrm{~g} / \mathrm{L}$ to API $5 \mathrm{~L} \mathrm{X} 42$ steel in $1 \mathrm{M} \mathrm{HCl}$. The adsorption of GA on the steel surface was found to obey Langmuir adsorption isotherm and involves physical adsorption. GA was also found to act as a mixed-type inhibitor. 
In an attempt to improving the inhibitive performance of naturally occurring polymers on the corrosion of metals in different aggressive environments, several modifications have been done. Ferkry and Mohamed [33] modified chitosan by incorporating acetyl thiourea and then evaluated the corrosion inhibition performance of the acetyl thiourea chitosan (ATUCS) on the corrosion behavior of mild steel in naturally aerated $0.5 \mathrm{M} \mathrm{H}_{2} \mathrm{SO}_{4}$ solution. ATUCS was found to show very good inhibition efficiency in $0.5 \mathrm{M} \mathrm{H}_{2} \mathrm{SO}_{4}$ solution and reaches $94.5 \%$ at $0.76 \mathrm{mM}$ concentration. Also, Li et al. [34] have modified chitosan with thiosemicarbazide (TSFCS) and thiocarbohydrazide (TCFCS). TSFCS and TCFCS were tested for protective ability on 304 steel corrosion in $2 \%$ acetic acid using potentiodynamic polarization measurements. The results show that both compounds act as mixed-type anticorrosion inhibitors for 304 steel in $2 \%$ acetic acid.

The physical and chemical properties of cassava starch have been modified and the compounds evaluated as corrosion inhibitors of carbon steel under alkaline conditions in $200 \mathrm{mg} / \mathrm{L} \mathrm{NaCl}$ solutions [35]. Two species were tested: an activated starch (AS) and a carboxymethylated starch (CMS) with two different degrees of substitution (DS). The inhibitive properties were studied by means of electrochemical impedance spectroscopy. It was found that modified starches have corrosion inhibitive properties and that their protection level depends on the type and amount of active groups present in the molecules. AS showed better inhibition efficiency than CMS and the extent of inhibiting ability was found to be dependent on the degree of substitution. It was found through the examination of the metal surface immersed in AS inhibited solution that a densification of the inhibitive layer was responsible for the higher protective influence exerted by AS. Banerjee et al. [36] chemically modified natural polysaccharide by grafting polyacrylamide with Okra mucilage and tested the modified polymer as corrosion inhibitor for mild steel in $0.5 \mathrm{M} \mathrm{H}_{2} \mathrm{SO}_{4}$ solution using gravimetric and electrochemical techniques. The inhibition efficiency was found to increase with increasing inhibitor concentration up to maximum of $96.6 \%$ for $100 \mathrm{ppm}$ at $25^{\circ} \mathrm{C}$.

Mobin [37] studied the corrosion inhibition of mild steel in sulphuric acid solution in presence of starch (polysaccharide) using weight loss and potentiodynamic polarization measurements in the temperature range of 30$60^{\circ} \mathrm{C}$. Starch moderately inhibits the corrosion of mild steel in the studied medium. The inhibitor was modified by adding a very small concentration of sodium dodecyl sulfate and cetyltrimethyl ammonium bromide and the effect of the addition on the corrosion inhibition behavior of starch were also examined. It was found that inhibition efficiency of starch was significantly improved by the addition of both surfactants. The effect of surfactants on the corrosion inhibition behavior of starch was found to be synergistic in nature. It was also observed that the inhibition efficiencies of starch alone and the modified starch decrease with rise in temperature. Iota-carrageenan a natural polymer has been reported as a corrosion inhibitor for aluminum in the presence of pefloxacinmesylate, acting as zwitterionic mediator, in acidic medium [38]. Significant improvement in inhibition efficiency of iota-carrageenan was observed in the presence of the mediator. Activation energy of corrosion and other thermodynamic parameters such as standard free energy, standard enthalpy, and standard entropy of the adsorption process revealed better and well-ordered physical adsorption layers in presence of pefloxacin. The adsorption of iota-carrageenan in the presence of pefloxacin mediator was found to follow the Langmuir isotherms. The adsorption of the inhibitor on the aluminum surface was confirmed with the aid of a scanning electron microscope (SEM).

The effect of addition of halide ions on corrosion inhibition potential of carboxymethyl cellulose (CMC) for mild steel in sulphuric acid solution has been reported [22]. Results obtained showed that addition of chloride ions to $\mathrm{CMC}$ antagonized the corrosion inhibition process whereas bromide and iodide ions exerted synergistic effect on the corrosion inhibition by CMC.

\section{SYNTHETIC POLYMERS AS CORROSION INHIBITORS OF MILD STEEL}

Synthetic polymers just like the naturally occurring polymers have received considerable attention as metal corrosion inhibitor. A close inspection of their structures (Table 2) revealed that they have polar functional group which is one of the requirements for an organic compound to qualify as a metal corrosion inhibitor. Two novel class of interesting polyurea derivatives designated as $6(\mathrm{a}-\mathrm{c})$ and 7 (a-c) have been synthesized using solution polycondensation technique by the interaction of one mole of bis (2aminothiazol-4-ylbenzylidene) cycloalkanones monomers with one moles of diisocyanate compounds in pyridine. The corrosion inhibition behaviors of the synthesized polymers on steel in $0.5 \mathrm{M} \mathrm{H}_{2} \mathrm{SO}_{4}$ solution at $40^{\circ} \mathrm{C}$ were tested [39]. It was found that polyurea designated 6a gives approximate constant values of inhibition efficiency at all the selected concentrations except in 1 and $2 \mathrm{ppm}$ while the designated 7a polyurea derivative inhibit the corrosion of steel in $0.5 \mathrm{M}$ $\mathrm{H}_{2} \mathrm{SO}_{4}$ solution at low concentration but accelerate at higher concentration.

The corrosion inhibition of mild steel in hydrochloric acid solution containing three different molecular weights of polyvinyl alcohol (PVA) designated PVA-I, PVA-II, and PVA-III corresponding to $14,000,72,000$, and $125,000 \mathrm{~g} / \mathrm{mol}$ respectively have been investigated using electrochemical impedance spectroscopy (EIS), linear polarization resistance (LPR), and potentiodynamic polarization (PDP) techniques at $25^{\circ} \mathrm{C}$ [40]. It was found that the different molecular weights of PVA inhibit the corrosion of mild steel in $\mathrm{HCl}$ environment and the extent of inhibition was dependent on concentration and molecular weight of the polymer. PVA was found to be a mixed-type inhibitor and its adsorption on the surface of mild steel followed Langmuir adsorption model. Physical adsorption mechanism was proposed for the mode of adsorption of the polymer on the mild steel surface. The inhibition efficiencies obtained for mild steel corrosion in $0.5 \mathrm{M} \mathrm{HCl}$ in the presence of different molecular weights PVA from EIS, LPR, and PDP measurements are summarized in Table 3 .

Atta et al. [41] have synthesized novel dispersed magnetite core-shell nanogel polymers and their effectiveness as corrosion inhibitors for carbon steel in $1 \mathrm{M}$ 
Table 2. Chemical structures of repeat units of some synthetic polymers used as corrosion inhibitors.

\begin{tabular}{|c|c|c|c|c|}
\hline Polymer (Inhibitor) & Chemical Structure of Repeat Unit & Type of Metal & Medium & References \\
\hline Polyethylene glycol & & $\begin{array}{l}\text { Mild steel; } \\
\text { Aluminium }\end{array}$ & $\mathrm{HCl}$ & $\begin{array}{c}{[53,62]} \\
{[67,68]}\end{array}$ \\
\hline polyurea & $--[\mathrm{NHCO}-\mathrm{R}-\mathrm{NHCO}--]_{\mathrm{n}}$ & Steel & & [39] \\
\hline Polyvinyl pyrrolidone & $-\mathrm{CH}_{2}-$ & $\begin{array}{l}\text { Carbon steel; } \\
\text { Mild steel; } \\
\text { Stainless steel }\end{array}$ & $\mathrm{NaCl}, \mathrm{HCl}$ & $\begin{array}{c}{[46] ;} \\
{[53,56]} \\
{[72]}\end{array}$ \\
\hline Poly vinyl alcohol & & Mild steel & $\mathrm{HCl}$ & {$[40,55,58,63]$} \\
\hline polypyrrole & & $\begin{array}{l}\text { Mild steel; } \\
\text { Aluminium; } \\
\text { Nickel }\end{array}$ & $\begin{array}{c}\mathrm{H}_{2} \mathrm{SO}_{4} \\
\mathrm{NaCl}\end{array}$ & $\begin{array}{l}{[45] ;} \\
{[69] ;} \\
{[79]}\end{array}$ \\
\hline Polyacrylic acid & & Aluminium & $\mathrm{H}_{2} \mathrm{SO}_{4}$ & {$[70]$} \\
\hline
\end{tabular}

Table 3. Inhibition efficiency for mild steel in $0.5 \mathrm{M} \mathrm{HCl}$ with PVA of different molecular weights from different techniques [40].

\begin{tabular}{|c|c|c|c|c|}
\hline \multirow{3}{*}{ Inhibitor } & \multirow{2}{*}{ Concentration (ppm) } & \multicolumn{3}{|c|}{ Inhibition Efficiency (\% I) } \\
\cline { 2 - 5 } & & EIS & LPR & PDP \\
\hline \hline \multirow{3}{*}{ PVA-I } & 50 & 65.77 & 58.59 & 28.83 \\
\cline { 2 - 5 } & 100 & 68.43 & 58.97 & 47.77 \\
\cline { 2 - 5 } & 500 & 73.52 & 64.43 & 53.40 \\
\hline \multirow{3}{*}{ PVA-II } & 1000 & 76.76 & 66.01 & 64.08 \\
\cline { 2 - 5 } & 50 & 63.96 & 41.15 & 1.91 \\
\cline { 2 - 5 } & 100 & 69.62 & 62.72 & 49.65 \\
\hline \multirow{3}{*}{ PVA-III } & 500 & 74.69 & 70.62 & 58.02 \\
\cline { 2 - 5 } & 1000 & 76.13 & 74.58 & 64.80 \\
\cline { 2 - 5 } & 50 & 65.31 & 51.28 & 16.66 \\
\cline { 2 - 5 } & 100 & 66.40 & 61.26 & 27.79 \\
\hline & 500 & 75.41 & 71.84 & 55.65 \\
\hline
\end{tabular}

$\mathrm{HCl}$ tested by potentiodynamic polarization and electrochemical impedance spectroscopy techniques. The results showed enhancement in inhibition efficiencies with increasing the inhibitor concentrations and temperatures. It was found that the nanogel particles act as mixed inhibitors and their mode of adsorption on the metal surface fit well into Langmuir adsorption isotherm. The inhibition properties of the electro-prepared Poly (o-phenylenediamine), P(oPD), on the corrosion rate of mild steel (MS) in $\mathrm{HCl}$ solutions have been investigated under different experimental conditions using weight loss and potentiodynamic polarization techniques [42]. The data obtained from the two techniques showed that the presence of $\mathrm{P}(\mathrm{oPD})$ in the acid solutions suppresses the corrosion rate of MS indicating that the polymer acts as corrosion inhibitor. The inhibition performance of the polymer was found to improve with increasing its concentration and decreasing the reaction temperature. The inhibition of mild steel corrosion was proposed to occur through adsorption and formation of barrier film of $\mathrm{P}(\mathrm{oPD})$ on the metal surface which separates the metal from direct contact with the corrosive medium and hence protects the metal against the corrosion.

Polymers used as mild steel corrosion inhibitors have been greatly modified. Hasanov et al. [43] studied the corrosion inhibitive efficiencies of two crown type polyethers, namely dibenzo-bis-imino crown ether $(\mathrm{C}-1)$ and dibenzo-diaza crown ether (C-2), which are macrocyclic Schiff base and its reduced form (macrocyclic amine), respectively, for steel in sulphuric acid solution by Tafel extrapolation and linear polarization methods. Corrosion and adsorption isotherm parameters were determined from current-potential curves. The studies show that C-1 and C-2 inhibit the corrosion of the steel in corrosive environment induced by sulphuric ions. Semi-empirical AM1 method was used for theoretical calculations and the result obtained from the calculations for the compounds were found to be consistent with the experimental findings. Hasanov et al. [44] have also reported on the effects of poly $(N-$ 
ethylaniline) (PNEA) monolayer coating and polypyrrole/ poly ( $N$-ethylaniline) (PPY/PNEA) as well as PNEA/PPY bilayer coatings formed on low carbon steel by electropolymerisation, on the corrosion of low carbon steel in $1 \mathrm{M}$ $\mathrm{H}_{2} \mathrm{SO}_{4}$ solution. From the report, it is found that the low carbon steel coated with polymer layers prevent the corrosion of bare low carbon steel in sulphuric acid solution. It is also found that PPY/PNEA and PNEA/PPY coatings inhibited the corrosion of low carbon steel in $1 \mathrm{MH}_{2} \mathrm{SO}_{4}$ solution better than the monolayer PNEA coating. The anticorrosion property of polypyrrole/phosphotungstate on low alloy steel in sea water has been reported [45].

Al Fuhaiman et al. [46] investigated the corrosion inhibition of carbon steel using polyvinyl pyrrolidone (PVP) in an aerated alkaline medium containing $0.1 \mathrm{M} \mathrm{NaCl}$ at $\mathrm{pH}$ 9 and 10. The influence of KI and untreated Saudi clay (UC) as additives on the inhibition efficiency of PVP was also studied. The results reveal that inhibition efficiencies of corrodent solutions with $1000 \mathrm{ppm}$ PVP ranged from 66$78 \%$ for weight loss results and $23-66 \%$ for the electrochemical measurements. It was found from electrochemical impedance results that the adsorption of PVP led to the formation of a protective film on the carbon steel $/ \mathrm{NaCl}$ solution interface. PVP was found to be a mixed type inhibitor. However, the addition of KI to PVP and the blank significantly enhanced the inhibition efficiency while the addition of UC affects the inhibiting ability of PVP negatively. Table 4 summarizes the influence of addition of KI and UC on the inhibitive force of PVP on carbon steel corrosion in $0.1 \mathrm{M} \mathrm{NaCl}$.

Table 4. The effect of addition of UC and KI to $1000 \mathrm{ppm}$ of PVP as inhibitor for carbon steel in $0.1 \mathrm{M} \mathrm{NaCl}$ solution at $30^{\circ} \mathrm{C}[46]$.

\begin{tabular}{|c|c|c|}
\hline System & $\mathbf{p H}$ & $\begin{array}{c}\text { Inhibition } \\
\text { Efficiency (\%I) }\end{array}$ \\
\hline \hline Blank + PVP & 9.0 & 51.68 \\
\hline Blank + PVP + 2g/L UC & 9.0 & 41.00 \\
\hline Blank + PVP + 6g/L UC & 9.0 & 36.63 \\
\hline Blank + PVP & 10.0 & 63.70 \\
\hline Blank + PVP + 2g/L UC & 10.0 & 58.40 \\
\hline Blank + PVP + 6g/L UC & 10.0 & 52.19 \\
\hline Blank + PVP + 0.02 M KI & 9.0 & 57.42 \\
\hline Blank + PVP + 0.06 M KI & 9.0 & 67.25 \\
\hline Blank + PVP + 0.02 M KI & 10.0 & 79.96 \\
\hline Blank + PVP + 0.06 M KI & 10.0 & 88.76 \\
\hline Blank + PVP + 0.06 M KI + 6g/L UC & 10.0 & 74.22 \\
\hline
\end{tabular}

The inhibiting ability of poly (acrylamide-co-4-vinylpyridine) copolymer (AM-4VP-9) on mild steel in $1 \mathrm{M}$ $\mathrm{H}_{2} \mathrm{SO}_{4}$ acid has been enhanced by the addition of iodide ions [47]. The results of the work reveal that the inhibition efficiency of AM-4VP-9 was synergistically improved by the addition of $\mathrm{KI}$ and the inhibiting effect of the system (AM-4VP-9 + KI) increased with increasing immersion time. Ashassi-Sorkhabi and Es'haghi [48] synthesized polyaniline/ nanodiamond (PANI/ND) nanocomposite coating on mild steel through electrochemical polymerization using cyclic voltammetry technique. The corrosion performance of the coating was studied in $3.5 \% \mathrm{NaCl}$ solution by electrochemical impedance spectroscopy (EIS), polarization, and salt spray methods. The results show that the presence of ND particles remarkably improved the corrosion protection performance of the PANI films in corrosive $3.5 \% \mathrm{NaCl}$ medium. It was found from EIS and polarization measurements that the coating resistance and corrosion resistance values for PANI/ND nanocomposite coating were much higher than that of pure PANI-coated electrode. It was also found that the protection efficiency of PANI/ND-coated mild steel could reach $90 \%$ after 3 days. Similarly, the protective ability of polyaniline/nanodiamond (PANI/ND) nanocomposite for mild steel in $0.5 \mathrm{M} \mathrm{H}_{2} \mathrm{SO}_{4}$ solution have been tested using electrochemical impedance spectroscopy and polarization techniques [49]. The results showed that the presence of ND particles greatly improved the corrosion performance of the PANI films on mild steel surface in $0.5 \mathrm{M} \mathrm{H}_{2} \mathrm{SO}_{4}$ solution. For example, PANI alone was found to afford $82.7 \%$ protection to mild steel in the corrosive medium while PANI/ND offered $93.3 \%$ efficiency.

The effect of the addition of poly (4-vinylpyridinehexadecyl bromide) P4VP-Alkyl 50\% newly synthesized on the corrosion of mild steel in $1 \mathrm{M} \mathrm{HCl}$ has been assessed by weight loss, linear potential scan voltammetry (I - E), and electrochemical impedance spectroscopy (EIS) [50]. It was found that the polymer reduces the corrosion rate of mild steel in $1 \mathrm{M} \mathrm{HCl}$ and the inhibition efficiency increased with increase in the polymer concentration and attained $95 \%$ at a concentration of $300 \mathrm{mg} / \mathrm{L}$. The polymer was found to adsorb on the metal surface according to Langmuir adsorption isotherm model and influences specifically the cathodic reactions. Karthikaiselvi and Subhashini [51] have reported the influence of poly (vinyl alcohol-o-methoxy aniline) PVAMOA composite on the corrosion behavior of mild steel in $1 \mathrm{M} \mathrm{HCl}$ at $303-343 \mathrm{~K}$. It is found from the report that the inhibition efficiency of the polymer increases as the temperature rises from $303-323 \mathrm{~K}$ but tends to decrease at higher temperatures. It was found that the adsorption of PVAMOA on the metal surface obeyed Langmuir and ElAwady adsorption isotherms. The adsorption of the composite on the mild steel surface was established by scanning electron microscope.

Ali et al. [52] studied the corrosion inhibition of monomers, its precursor, and the resulting polymers (Fig. 2) on mild steel corrosion in acidic and saline media at $60^{\circ} \mathrm{C}$ using gravimetric and electrochemical methods.

The inhibition of mild steel corrosion in aerated acid mixture of $0.05 \mathrm{~N} \mathrm{H}_{2} \mathrm{SO}_{4}$ and $0.5 \mathrm{~N} \mathrm{HCl}$ solutions by polyvinyl pyrrolidone (PVP) and polyethylene glycol (PEG) has been assessed using potentiodynamic polarization, linear polarization, electrochemical impedance spectroscopy, adsorption, and surface morphological studies [53]. It was found that the presence of PEG and PVP decreases the double - layer capacitance and increases the charge-transfer resistance. Inhibition efficiency increased significantly with increase in the additives concentration. The inhibitor molecules were found to adsorb on the metal surface following Langmuir adsorption isotherm model. Both PEG 


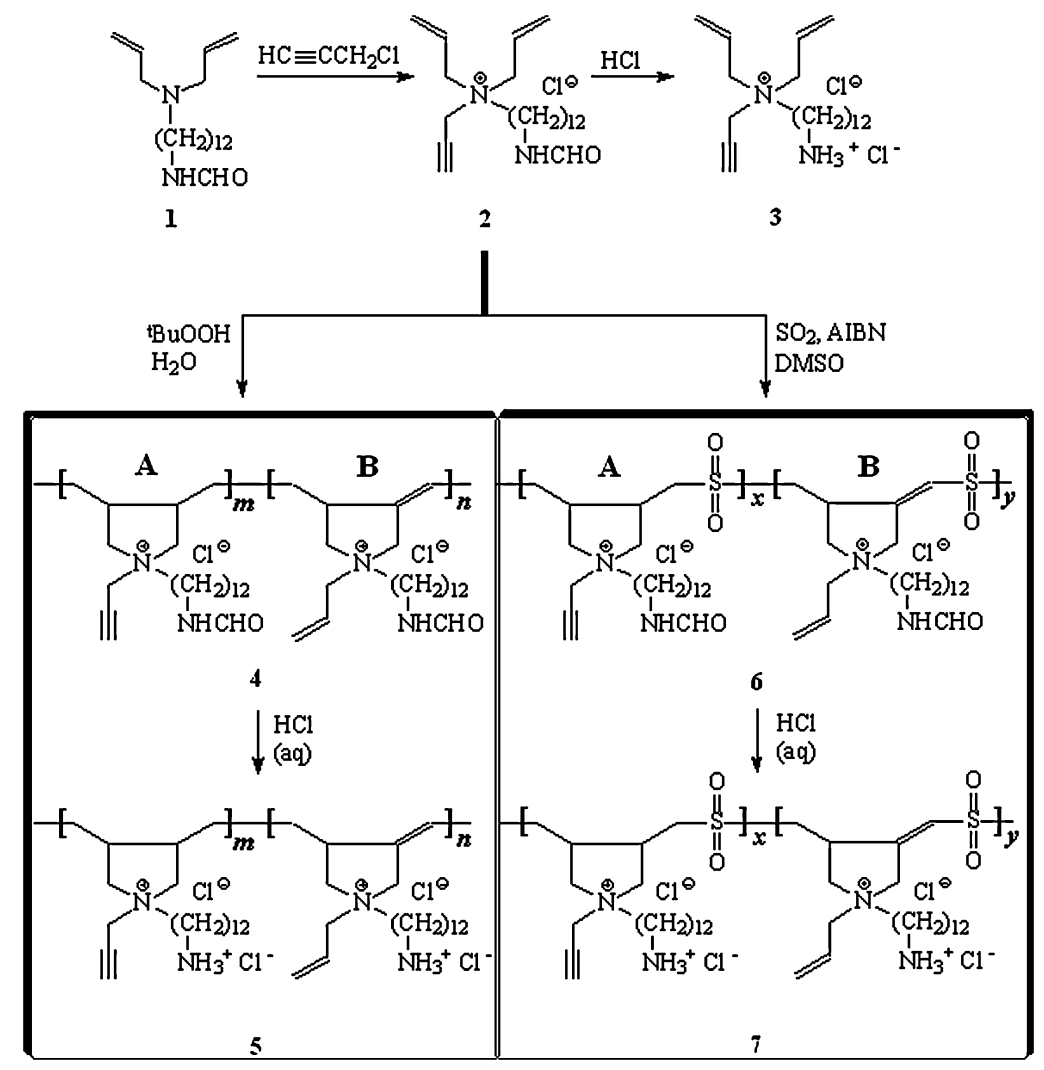

Fig. (2). Scheme for the synthesis of monomers and cyclopolymers [52].

and PVP were found to afford good inhibition of mild steel corrosion in acidic medium and act as mixed type inhibitors. Surface analysis which was done with the aid of scanning electron microscope and atomic force microscope reveal that PVP offer better inhibition to mild steel surface than PEG. Qian et al. [54] modified polyaspartic acid (PASP) which was used as inhibitor for mild steel corrosion in $0.5 \mathrm{M}$ $\mathrm{H}_{2} \mathrm{SO}_{4}$ solution by adding KI. The inhibition efficiency PASP was found to be significantly enhanced by this modification. Result of the zero charge potential measurements shows that iodide ions promote the film formation of PASP greatly.

Poly (vinyl alcohol-aniline) PVAA composite has been tested for its performance in protecting mild steel against corrosion in $1 \mathrm{M} \mathrm{HCl}$ [55] by means of weight loss, electrochemical polarization, and electrochemical impedance methods. Results indicate that the addition of PVAA to the acid retard the dissolution of the metal. Inhibition was found to be due to the adsorption of PVAA on the mild steel surface and increase with increasing concentration of the inhibitor. Polarization results indicate that PVAA is a mixed type inhibitor and its adsorption onto the metal surface follows Langmuir and Temkin adsorption isotherms. Karthikaiseli and Subhashini [56] in an attempt to overcome the limitation of insolubility of polymethyl aniline (PMA) converted PMA into a water-soluble composite by using supporting polymer polyvinylpyrrolidone to get higher solubility and corrosion inhibition efficiency. The corrosion inhibitive effect of the water-soluble composite poly (vinyl pyrrolidone-methyl aniline) on mild steel in $1 \mathrm{M} \mathrm{HCl}$ was assessed by weight loss and electrochemical techniques. The water-soluble composite was found to affect both the anodic and cahtodic processes and acts as a mixed type inhibitor. The adsorption of the inhibitor obeys the Langmuir adsorption model and more strictly follow El-Awady adsorption isotherm. Also, the inhibition efficiency of the inhibitor was found to increase as the temperature increases from $303-333 \mathrm{~K}$ but decreases at temperature exceeding $333 \mathrm{~K}$.

The report on the inhibition action of polyvinyl alcoholsulphanilic acid (PVASA) composite on the corrosion of commercial mild steel in $1 \mathrm{M} \mathrm{HCl}$ medium [57] reveal that PVASA composite acts as an inhibitor for mild steel in acid environment. The inhibition efficiency was found to increase with increase in the concentration of the inhibitor and attain a maximum of $84 \%$ at $6000 \mathrm{ppm}$. PVASA composite was also found to acts as a mixed inhibitor and adsorb on the metal surface according to the model of Langmuir isotherm. The corrosion inhibition of behavior of mild steel in $0.1 \mathrm{M}$ $\mathrm{H}_{2} \mathrm{SO}_{4}$ in the presence of polyvinyl alcohol (PVA) has been investigated by means of weight loss and potentiodynamic polarization measurements in the temperature range of $3060^{\circ} \mathrm{C}$ [58]. Inhibition efficiency of PVA increases as the concentration increases and shows a maximum of $81.41 \%$ at $30^{\circ} \mathrm{C}$ at $100 \mathrm{mg} / \mathrm{L}$ but decreased with rise in temperature. PVA was modified by adding very small amount of surfactants namely sodium dodecyl sulphate (SDS) and cetylpyridinium chloride (CPC). It was found that the addition synergistically enhanced the inhibiting action of PVA. The calculated synergism parameter was found to be greater than unity in all cases. The adsorption of PVA alone and in combination with surfactants followed Langmuir isotherm. 
Azghandi et al. [59] have studied the corrosion inhibitive action of an environmentally friendly water-base acrylic terpolymer [methyl methacrylate/butyl acrylate/acrylic acid (ATP)] on mild steel in $1 \mathrm{M} \mathrm{HCl}$ by alternating current, direct current and quantum chemical methods. An inhibition efficiency of more than $97 \%$ was obtained with $0.8 \mathrm{mmol} / \mathrm{L}$ ATP. It is found from the report that increases in inhibitor concentration and immersion time has a positive effect on the inhibition efficiency of the inhibitor while temperature has negligible influence. The terpolymer was found to obey Langmuir adsorption isotherm and adsorb onto the mild steel surface via chemical adsorption mechanism. Three terpolymer derived from resorcinol and formaldehyde and diaminoethane (TER - 1), urea (TER - 2), and thiourea (TER - 3) have been synthesized and their inhibitive performance on mild steel in $1 \mathrm{M} \mathrm{HCl}$ investigated [60] using electrochemical impedance, potentiodynamic polarization, linear polarization, and gravimetric techniques. Inhibition efficiency of the inhibitors followed the order TER-3 $>$ TER$2>$ TER-1 and the terpolymers were found to be mixed type inhibitors. Barak et al. [61] used high molecular weight poly (ethylene oxide) to synthesize telechelic bromide terminated poly (ethylene oxide) polymers. The low molecular weight polystyrene anion was generated by living anionic polymerization and the living polystyrene anion was reacted with telechelic bromide terminated poly (ethylene oxide) polymers to obtain water-soluble polystyrene- $b$-poly (ethylene oxide)- $b$-polystyrene triblock copolymers. The inhibitive effect of the triblock copolymer on mild steel corrosion in $1 \mathrm{M} \mathrm{H}_{2} \mathrm{SO}_{4}$ acid solution was studied using potentiodynamic polarization technique. The investigated results reveal that the corrosion rate of mild steel in the sulphuric acid medium decreased significantly as the concentration of the triblock copolymer was increased. Polarization study shows that the inhibitor acted as a mixed type inhibitor. Table 5 shows the influence of inhibitor concentration and temperature on the inhibition efficiency of the studied triblock copolymers.

The adsorption and corrosion inhibition behavior of polyethylene glycol (PEG) alone and in the presence of surfactants sodium dodecyl benzene sulphate (SDBS) and cetyltrimethyl ammonium bromide (CTAB) on mild steel corrosion in $0.1 \mathrm{M} \mathrm{H}_{2} \mathrm{SO}_{4}$ in temperature range of $303-333 \mathrm{~K}$ has been reported [62]. From the results of the report, inhibition efficiency is concentration dependent and attains maximum value of $86.91 \%$ at $303 \mathrm{~K}$ at $25 \mathrm{ppm}$. The surfactants were found to synergistically improve the inhibiting ability of the inhibitor. Poly(vinyl alcohol-leucine) composite (PVAL) hasbeen synthesized and its influence on corrosion inhibition of mild steel in $1 \mathrm{M}$ hydrochloric acid solution studied by weight loss and potentiodynamic polarization techniques [63]. The composite (PVAL) was found to show more than $95 \%$ inhibition efficiency at an optimum concentration of $0.6 \%$ by weight. The inhibition efficiency of the inhibitor was found to vary with inhibitor concentration, solution temperature, and immersion time. Potentiodynamic polarization studies revealed that PVAL acted as a mixed type inhibitor. It was also found that addition of $10^{-2} \mathrm{M}$ KI to the composite could step-up the inhibition efficiency to as high as $99.2 \%$.
Table 5. Inhibition efficiency of triblock copolymer in $1 \mathrm{M}$ $\mathrm{H}_{2} \mathrm{SO}_{4}$ at temperature range of $298-328 \mathrm{~K}$ [61].

\begin{tabular}{|c|c|c|}
\hline $\begin{array}{c}\text { Temperature } \\
\text { (K) }\end{array}$ & $\begin{array}{l}\text { Inhibitor Concentration } \\
(\text { (ppm) }\end{array}$ & $\begin{array}{c}\text { Inhibition Efficiency } \\
(\% \mathrm{I})\end{array}$ \\
\hline \multirow{4}{*}{298} & 400 & 82.62 \\
\hline & 800 & 90.66 \\
\hline & 1200 & 96.26 \\
\hline & 1600 & 98.72 \\
\hline \multirow{4}{*}{308} & 400 & 80.31 \\
\hline & 800 & 86.68 \\
\hline & 1200 & 92.12 \\
\hline & 1600 & 96.17 \\
\hline \multirow{4}{*}{318} & 400 & 62.66 \\
\hline & 800 & 69.04 \\
\hline & 1200 & 80.37 \\
\hline & 1600 & 94.09 \\
\hline \multirow{4}{*}{328} & 400 & 59.76 \\
\hline & 800 & 63.16 \\
\hline & 1200 & 66.48 \\
\hline & 1600 & 69.46 \\
\hline
\end{tabular}

Subhashini et al. [64] chemically synthesized poly(vinyl alcohol-threonine) [PVAT] water soluble composite and investigated its corrosion inhibition performance for mild steel corrosion in $1 \mathrm{M} \mathrm{HCl}$ using chemical andelectrochemical techniques. The results showed that the presence of composite in the acid solution significantly suppress the dissolution of mild steel in the corrosive medium. Inhibition efficiency of $96.58 \%$ at $0.60 \%$ of the composite was obtained from electrochemical impedance measurements. The inhibition efficiency of the composite was found to vary directly as the concentration. Potentiodynamic polarization studies suggested that the composite functioned as mixed type inhibitor. However, the inhibition mechanism of the composite in hydrochloric acid medium was explained on the basis of molecular adsorption. This has to do with organic compounds inhibiting metal corrosion by controlling both anodic and cathodic reactions. In most of the cases, the heteroatoms present in the inhibitor molecules are protonated in acidic solution and are converted into quaternary / oxonium ions. These protonated species get adsorbed on the cathodic sites of the mild steel and retard the hydrogen evolution and/or to anodic sites through chloride ion interbridge thereby preventing the metal dissolution [65]. The chloride ions from the corrosive environment may gradually substitute the water molecules and get adsorbed on the mild steel surface. The adsorbed chlorideions create excess negative charge on the metal surface and thus stimulate the adsorption of protonated specie on the metal surface. This process is sometimes referred to as anion induced adsorption. The author attributed the high inhibition performance of the composite to the presence of nitrogen 
atom, large number of oxygen atoms, larger molecular size, and linearity in the polymeric chain.

\section{SYNTHETIC POLYMERS AS CORROSION INHIBITORS OF ALUMINUM}

The corrosion behavior of aluminum with two different microstructures namely, polycrystalline (pc-Al) and microcrystalline aluminum coating (mc-Al) fabricated from the polycrystalline Al target by magnetron sputtering in 0.1 $\mathrm{M} \mathrm{H}_{2} \mathrm{SO}_{4}$ and the inhibiting effect of polyacrylamide (PA) on the corrosion of these microstructures have been reported [66]. From the report, it is found that surface microcrystallization increases the corrosion susceptibility of aluminum leading to increase in the kinetics of the anodic dissolution. PA was found to retard the dissolution of both samples. Inhibition efficiency of PA was found to be concentration dependent and was more pronounced on the mc-Al specimen.

Abdallab et al. [67] have studied the inhibition of corrosion of aluminum in $0.5 \mathrm{M} \mathrm{HCl}$ solution by polyethylene glycol compounds (PEG) with different molecular weight $(600,2000,6000 \mathrm{~g} / \mathrm{mol})$ using weight loss measurement, galvanostatic, and potentiodynamic anodic polarization techniques. The results show that the inhibition efficiency of PEG increases with increase in concentration and decreases with rise in temperature. The inhibiting ability of PEG was found to depend on the chemical structure, concentration of the inhibitor, and the experimental temperature. It was also found that the molecular weight of the inhibitor affected the inhibition efficiency in the order: PEG $600<$ PEG2000<PEG6000. Inhibition was attributed to the adsorption of the inhibitor on the aluminum surface and the adsorption pattern was found to obey Temkin adsorption model. Also, it was found that PEG protects aluminum surface pitting attack in $\mathrm{HCl}$ solution by shifting the pitting corrosion potential to more noble direction. The inhibition performance of PEG for aluminum corrosion has also been reported by Awad et al. [68] but in $1.0 \mathrm{M} \mathrm{HCl}$. The results agreed with the findings of Abdallab et al. [69] that PEG is a good inhibitor for aluminum in $\mathrm{HCl}$ medium. It was found that PEG acts as a mixed type inhibitor.

Polymer modification has continued to serve as a mean of optimizing polymer inhibiting ability. Zor et al. [70] deposited polypyrrole on the aluminum surface in different anions $\left(\mathrm{CO}_{3}^{2-}, \mathrm{NO}_{2}^{-}, \mathrm{CrO}_{4}^{2-}, \mathrm{DBS}^{-}\right)$and the contribution of anions to formation of polypyrrole film as well as the effect of film on the corrosion behavior of aluminum in $0.1 \mathrm{M} \mathrm{HCl}$ solution were undertaken using cyclic voltammetry and potentiostatic techniques, respectively. Results revealed that the films significantly inhibit pitting corrosion of aluminum in $0.1 \mathrm{M} \mathrm{HCl}$ solution with the $\mathrm{CrO}_{4}^{2-} /$ polypyrrole film being most effective. The films inhibition efficiencies are summarized in Table $\mathbf{6}$.

Umoren et al. [71] elucidated the corrosion inhibition mechanism of aluminum in $\mathrm{H}_{2} \mathrm{SO}_{4}$ solution by polyacrylic acid (PAA) in the absence and presence of iodide ions by using in-situ atomic force microscopy (AFM) technique. Results obtained indicated that PAA inhibited the corrosion of aluminum by adsorption onto the aluminum surface. Iodide ions were found to significantly improve the inhibitive power of PAA and this was attributed to the existence of synergistic effect between iodide ions and PAA. It was deduced from the in situ AFM morphology study that PAA in the presence of iodide ions was adsorbed on aluminum surface after taking a more ordered arrangement, providing a uniform coverage at potential below and above potential of zero charge.

Table 6. Inhibition efficiency of polypyrrole (PPy) anions film on aluminum corrosion in $0.1 \mathrm{M} \mathrm{HCl}[66]$.

\begin{tabular}{|c|c|}
\hline System & Inhibition Efficiency \\
\hline \hline $\mathbf{P P y} / \mathrm{NO}_{2}^{-} / \mathbf{A l}$ & 90.7 \\
\hline $\mathbf{P P y} / \mathrm{CO}_{3}^{2-} / \mathbf{A l}$ & 92 \\
\hline $\mathbf{P P y} / \mathrm{CrO}_{4}^{2-} / \mathbf{A l}$ & 99 \\
\hline $\mathbf{P P y} / \mathrm{DBS}^{-} / \mathrm{Al}$ & 86 \\
\hline
\end{tabular}

The inhibition effect of 3-(12-sodiumsulfonate dodecyloxy) aniline monomeric surfactant $\left(\mathrm{MC}_{12}\right)$ and its analog polymer poly 3-(dodecyloxy sulfonic acid) aniline $\left(\mathrm{PC}_{12}\right)$ on the corrosion of aluminum in $0.5 \mathrm{M} \mathrm{HCl}$ solution have been investigated using weight loss and potentiodynamic polarization methods [72]. It was found that the two compounds suppress the corrosion rate of aluminum in $0.5 \mathrm{M} \mathrm{HCl}$ without modifying the mechanism of corrosion process. Both the anodic and cathodic reactions were affected by these inhibitors, but the effect on the anodic reaction was more pronounced. Inhibition efficiency was also found to increase with increasing inhibitor concentration but decrease with raising temperature. The experimental data fit well into Langmiur and Frunkin adsorption isotherms.

\section{SYNTHETIC POLYMERS AS CORROSION INHIBITORS OF STAINLESS STEEL}

The inhibitive effects of polyvinylpyrrolidone PVP10 (mol. wt. 10,000) and PVP45 (mol. wt. 45, 000) on the corrosion behavior of $316 \mathrm{~L}$ stainless steel at different inhibitor concentrations and temperatures have been evaluated [73] using electrochemical techniques. The results obtained show that the inhibition effect of polyvinylpyrrolidone increases with increasing concentration and molecular weight. The highest inhibition efficiency of PVP45 was $96.9 \%$ at $0.05 \mathrm{~mol} / \mathrm{L}$ while the highest concentration of PVP10 offered inhibition of $42.7 \%$. PVP45 was found to show unstable current/voltage and current/time behavior which was indicative of frequent dissolution/ passivation events. Pitting was observed in all cases and accompanied by general surface corrosion in the case of PVP10. Shinde and Patil [74] electrochemically synthesized poly (o-toluidine) (POT) coatings on 304 stainless steel using cyclic voltammetric technique. The coatings were characterized by Fourier transform infrared spectroscopy, UV-vis adsorption spectroscopy, and cyclic voltammetry. The corrosion performance of POT coating in aqueous $3 \mathrm{wt}$ $\%$ sodium chloride was then investigated by electrochemical (open circuit potential, potentiodynamic polarization, cyclic potentiodynamic polarization, and electrochemical impedance spectroscopy) measurements. It was found that POT coating on 304 stainless steel prevents general and localized 
corrosion, and reduces the exchange current density by almost a factor of 45 than the bare 304 stainless steel.

Oncul et al. [75] studied the inhibition of the corrosion of stainless steel in acidic solution by $N$-vinylimidazole monomer (NVI) and poly- $N$-vinylimidazole (PNVI) by using potentiodynamic polarization and electrochemical impedance spectroscopy methods. The stainless steel was coated with NVI and PNVI respectively, and their corrosion rates compared to the corrosion rate of the bare stainless steel. Results show that both NVI and PNVI inhibit the corrosion of stainless steel in $1 \mathrm{~N}$ sulphuric acid solution but with NVI being a better inhibitor than PNVI.

The protection performance of polyindole film on stainless steel has been enhanced via titanium dioxide precoating [76]. The characterization of the coatings was done using nuclear magnetic resonance and Fourier-transform infrared spectra. The corrosion protection ability of the coating was assessed in $3.5 \% \mathrm{NaCl}$ solution by electrochemical impedance spectroscopy and potentiodynamic measurements. Quantum calculations were employed to determine the theoretical parameters. The results obtained show good correlation between experimental and theoretical parameters. The polyindole-enhanced film was found to offer excellent protection to stainless steel in $3.5 \% \mathrm{NaCl}$ solution.

Leon-Silva et al. [77] have investigated the effect of thermal annealing of poly(3-octylthiophene)(P3OT) coatings on the corrosion inhibition of stainless steel in $\mathrm{NaCl}$ solution. P3OT was synthesized by direct oxidation of the 3octylthiophenemonomer with ferric chloride $\left(\mathrm{FeCl}_{3}\right)$ as oxidant. P3OT films were deposited by drop-casting technique onto the 304 stainless steel electrode (304SS) and 304SS coated with P3OT films were thermally annealed during $30 \mathrm{~h}$ at different temperatures $\left(55^{\circ} \mathrm{C}, 80^{\circ} \mathrm{C}\right.$, and $100^{\circ} \mathrm{C}$ ). The corrosion resistance of stainless steel coated with P3OT in $0.5 \mathrm{M} \mathrm{NaCl}$ aqueous solution at room temperature was then evaluated by means of potentiodynamic polarization curves, linear polarization resistance, and electrochemical impedance spectroscopy. It is found from the result that the thermal treatment at $80^{\circ} \mathrm{C}$ and $100^{\circ} \mathrm{C}$ of P3OT films improved the corrosion resistance of the stainless steel in $\mathrm{NaCl}$ solution; the speed of corrosion diminished in an order of magnitude with regard to the 304SS. Morphological study show that when the films were heated, the grain size increased and a denser surface was obtained, which benefited the barrier properties of the film. Poly(3,4-ethylenedioxythiophene) (PEDOT) coatings have been electrochemically prepared on stainless steel (SS) in acetonitrile and aqueous media, respectively, by the cyclic voltammetry technique [78]. The corrosion behavior of the coated SS was studied in $3.5 \mathrm{wt} \% \mathrm{NaCl}$ solution using anodic polarization and electrochemical impedance spectroscopy and the results indicate that the polymer coatings were able to mitigate the corrosion of the SS substrate in chloride solution. PEDOT works as the electron exchange medium to passivate the SS underneath and reduce the oxygen on the surface. The corrosion performances of different mole ratios of synthesized poly $\{(N$-methacryloyloxymethyl)benzotriazoleco- $N$-vinylpyrrolidone $\}$ coated on low nickel stainless steel specimens has been investigated in $1 \mathrm{M} \mathrm{H}_{2} \mathrm{SO}_{4}$ using potentiodynamic polarization, electro- chemical impedance method, and chronoamperometric studies [79]. Surface and morphological investigation were also carried out to characterize the adherence and uniformity of the coatings. Electrochemical corrosion test and surface analysis results show that the copolymer-coatings serve as a stable host matrix on low nickel stainless steel.

\section{SYNTHETIC POLYMERS AS CORROSION INHIBITORS OF OTHER METALS}

The electrosynthesis of polypyrrole (PPy) films on nitinol from solutions containing different corrosion inhibitors has been reported [80]. The corrosion behavior of the coated samples was studied in $0.15 \mathrm{M} \mathrm{NaCl}$. It was found that the presence of molybdate ions in the polymer matrix confers to the substrate a higher resistance to pitting corrosion. The polymer formed potentiostatically in a solution at $\mathrm{pH} 12$ containing nitrate and molybdate ions was found to be the most efficient in terms of adhesion and corrosion protection. Huang et al. [81] have synthesized acrylic acidallypolyethoxy carboxylate copolymer of different degree of polymerization (AQn: $n=5$ to 15 ) and the anti-scale property of the copolymer towards $\mathrm{CaCO}_{3}$ and iron (III) in artificial cooling water tested through static scale inhibition tests. The results show that both $\mathrm{CaCO}_{3}$ and iron (III) inhibition increase with increasing the degree of polymerization of $\mathrm{AQ} n$. It was found that the dosage of $\mathrm{AQ} n$ plays an important role on $\mathrm{CaCO}_{3}$ and iron (III) inhibition. The percentage inhibition of $\mathrm{AQ} n$ at different dosage was compared to the percentage inhibition of commercial inhibitors \{poly (acrylic acid, PAA, 1800 MW) and hydrolyzed polymaleic acid, HPMA, $600 \mathrm{MW}$ \} as shown in Table 7.

Pruna and Pilan [82] have used galvanostatic electrodeposition mode to synthesize polyaniline and polypyrrole - based composite coatings (PANI/PPy) onto pure zinc electrode. Potentiodynamic polarization, open circuit potential measurements, and electrochemical impedance spectroscopy were used to assess the corrosion inhibition ability of these composite coatings on pure zinc in chloride environment. It was found that coatings deposited at lower current density show the best quality in terms of protection ability towards zinc in aggressive chloride medium. It was also found that PANI/PPy composite coatings have better inhibiting ability than the homopolymer coatings.

The corrosion inhibition behavior of poly (pyrrole- $\mathrm{co}-\mathrm{N}$ methylpyrrole) films on copper corrosion in $3.5 \%(\mathrm{w} / \mathrm{v})$ $\mathrm{NaCl}$, synthesized from oxalic acid solutions containing different ratios of monomers (Py : NMPy 8:2, 6:4, 5:5, 4:6, $2: 8)$ has been examined [83] using potentiodynamic polarization and electrochemical impedance spectroscopy techniques. It was found that the synthesized copolymer films exhibit significant protection efficiency against corrosion of copper in alkaline environment and the $8: 2$ ratios of monomers were found to give the most protective copolymer coating.

Manimaran et al. [84] studied the inhibition efficiency of Polyacrylamide (PAA) in controlling corrosion of carbon steel in ground water in the absence and presence of $\mathrm{Zn}^{2+}$ using weight loss method. The formulation consisted of 250 ppm PAA and $50 \mathrm{ppm} \mathrm{Zn}^{2+}$ was found to have $98 \%$ 
Table 7. Calcium carbonate and iron (III) inhibitions of AQ15, PAA, and HPMA [80].

\begin{tabular}{|c|c|c|c|c|c|c|}
\hline \multirow{2}{*}{ Dosages of Scale Inhibitors $(\mathrm{mg} / \mathrm{L})$} & \multicolumn{3}{|c|}{ Calcium Carbonate Inhibition (\%) } & \multicolumn{3}{|c|}{ Transmittance of Solution (\%) } \\
\hline & AQ15 & PAA & HPMA & AQ15 & PAA & HPMA \\
\hline 0 & 0 & 0 & 0 & 100 & 100 & 100 \\
\hline 2 & 12.1 & 16.8 & 14.3 & 97.7 & 99.7 & 100 \\
\hline 4 & 52.6 & 31.7 & 20.8 & 91.6 & 35.8 & 99.7 \\
\hline 6 & 82.4 & 44.2 & 33.7 & 27.3 & 35.3 & 99.3 \\
\hline 8 & 98.5 & 52.1 & 50.6 & 16.8 & 34.9 & 98.9 \\
\hline 10 & 98.5 & 61.2 & 58.9 & 16.5 & 34.5 & 98.5 \\
\hline 12 & 97.8 & 74.9 & 67.6 & 15.9 & 35.2 & 95.1 \\
\hline 14 & 98.2 & 78.3 & 76.5 & 15.3 & 34.1 & 93.9 \\
\hline 16 & 97.5 & 79.7 & 83.4 & 15.5 & 33.7 & 94.8 \\
\hline
\end{tabular}

protection ability. The authors found that the inhibition efficiency of PAA increases by the addition of $\mathrm{Zn}^{2+}$ ion. A synergistic effect was seen to exist between PAA and $\mathrm{Zn}^{2+}$. The authors proposed that when carbon steel was immersed in ground water by $250 \mathrm{ppm}$ PAA and $50 \mathrm{ppm} \mathrm{Zn}^{2+}$ system, PAA $-\mathrm{Zn}^{2+}$ complex in solution was formed. PAA $-\mathrm{Zn}^{2+}$ complex diffused from the bulk of the solution towards the metal surface. PAA - $\mathrm{Zn}^{2+}$ complex was then converted into PAA - $\mathrm{Fe}^{2+}$ complex on the anodic sites of the metal surface with the release of $\mathrm{Zn}^{2+}$.

$\mathrm{Zn}^{2+}-\mathrm{PAA}+\mathrm{Fe}^{2+} \longrightarrow \mathrm{Fe}^{2+}-\mathrm{PAA}+\mathrm{Zn}^{2+}$

The released $\mathrm{Zn}^{2+}$ combines with $\mathrm{OH}^{-}$to form $\mathrm{Zn}(\mathrm{OH})_{2}$ on the cathodic sites of the metal surface.

$\mathrm{Zn}^{2+}+2 \mathrm{OH}^{-} \longrightarrow \mathrm{Zn}(\mathrm{OH})_{2}$

The protective film was thus believed to consist of $\mathrm{Fe}^{2+}$ PAA complex and $\mathrm{Zn}(\mathrm{OH})_{2}$. In near neutral aqueous solution, the authors proposed that the anodic reaction was the formation of $\mathrm{Fe}^{2+}$. This anodic reaction was controlled by the formation of PAA - $\mathrm{Fe}^{2+}$ complex on the anodic site of the metal surface. They believed that the cathodic reaction was the generation of $\mathrm{OH}^{-}$which was controlled by the formation of $\mathrm{Zn}(\mathrm{OH})_{2}$ on the cathodic sites of the metal surface.

$\mathrm{Fe} \rightarrow \mathrm{Fe}^{2+}+2 \mathrm{e}^{-}$(Anodic reaction)

$\mathrm{Fe}^{2+}+\mathrm{Zn}^{2+}$ - PAA complex $\rightarrow \mathrm{Fe}^{2+}$ - PAA complex +

$\mathrm{Zn}^{2+} \mathrm{O}_{2}+2 \mathrm{OH}^{-}+4 \mathrm{e}^{-}$

(Cathodic reaction)

$\mathrm{Zn}^{2+}+2 \mathrm{OH}^{-} \rightarrow 4 \mathrm{OH}^{-}$

Equation (8) accounts for the synergistic effect of PAA $\mathrm{Zn}^{2+}$ system.

Omrani et al. [85] synthesize dpolypyrrole (PPy) coatings on copper by electrochemical polymerization of pyrrole monomer in aqueous acidic and basic solutions by cyclic voltammetry. The coatings were characterized with $\mathrm{CV}$, UV-visible absorption spectroscopy, Fourier transform infrared (FT-IR) spectroscopy, and scanning electron microscopy (SEM) techniques. The authors investigated the corrosion protection aspects of PPy coatings using the potentiodynamic polarization technique and electrochemical impedance spectroscopy (EIS). It was found from the potentiodynamic polarization measurements that the PPy coating has ability to protect the copper against corrosion. They observed that $\mathrm{Cu} / \mathrm{PPy}$ in trisodium citrate solution could afford $70 \%$ protection of the metal surface whereas $\mathrm{Cu} / \mathrm{PPy}$ in chloroacetic acid solution could only afford $25 \%$ protection of the metal surface. However, the authors concluded that a complete corrosion protective PPy film could not be obtained through direct electro-oxidation procedure. This was attributed to copper dissolution in the monomer oxidation potential range.

\section{MECHANISM OF INHIBITION BY POLYMERS}

The extent of metal corrosion inhibition by organic inhibitors is dependent upon the ability of the inhibitor to get adsorbed and form an impact film on the metal surface. The process of inhibition begins with the displacement of hydrated water by the inhibitor species leading to specific adsorption of the inhibitor on the metal surface. However, certain properties such as the nature and charge of the metal, chemical structure of the inhibitor, and the type of corrosion inducing environment influenced the adsorption process. As could be seen from Tables $\mathbf{1}$ and $\mathbf{2}$, the studied polymers have heteroatoms in their functional groups thus justifying their selection as metal corrosion inhibitors. The heteroatoms in these functional groups could serve as the interaction center between the metal surface and the inhibitor molecule. As noted by Khairou and El-Sayed [86], the presence of heteroatoms in functional groups within inhibitor molecule could make bridges between the molecule and the metal surface, as a consequence, decrease corrosion rate. Moreover, the presence of lone pairs of electrons on the heteroatom(s) may enhance the interaction between the inhibitor and the positive surface of the metal.

Two forms of adsorption are consistent with organic inhibitors: physical and chemical adsorption. Physisorption is consistent with the electrostatic interaction between charged molecules and the charged metal surface while chemisorptions involves charge sharing or transfer from organic molecule to the metal surface to form coordinate type of bond. Results of most researches [16, 22, 25, 31, 35] showed that most polymers exist as polycations in acid medium (most studied environment). This makes it difficult for the polycations to approach the positively charge metal 
surface. Therefore, anions in the aqueous medium with smaller degree of hydration will first adsorb on the metal surface, bringing excess negative charge close to the interface and favoring further adsorption of polycations via electrostatic attraction. Hence, physical adsorption mechanism is mostly proposed for most of the studied polymers studied [16, 22, 25, 31, 35]. However, in cases where chemical adsorption mechanism prevails, Umoren et al. [26] explain that the inhibitor molecules exist as protonated species in equilibrium with the corresponding neutral species. The cationic and neutral molecules then become adsorb on the positively charged metal surface by displacing water molecules from the metal surface and the sharing of electron between free electrons of the heteroatoms and vacant orbitals of the metal take place.

\section{QUANTUM CHEMICAL STUDIES MOLECULAR MODELING APPROACHES}

AND

Quantum chemical methods have shown to be very useful in determining the molecular structure as well as elucidating the electronic structure and reactivity [87, 88]. Consequently, it has become a common practice to carry out quantum chemical calculations in corrosion inhibition studies. Many efficient corrosion inhibitors are organic compounds containing heteroatoms such as nitrogen, oxygen, sulfur and $\pi$-bonds. It is generally accepted that corrosion inhibition efficiency of organic compounds is related to their adsorption properties. The adsorption of these molecules depend mainly on certain physicochemical properties of the inhibitor molecule such as, functional groups, steric factor, aromaticity, electron density at the donor atoms and p-orbital character of donating electrons, electronic structure of the molecules and the strength of interaction between the inhibitor and the metal surface. The organic inhibitor should not only donate electrons to the unoccupied d-orbital of the metal, but can also accept electrons from the d-orbital of the metal leading to the formation of a feed-back bond [89].

In the use of density functional theory (DFT) in corrosion inhibition studies of organic molecules, the important quantum chemical parameters of interest include the energy of the highest occupied molecular orbital $\left(\mathrm{E}_{\mathrm{HOMO}}\right)$, the energy of the lowest unoccupied molecular orbital ( $\left.\mathrm{E}_{\mathrm{LUMO}}\right)$, the HOMO-LUMO energy gap, the dipole moments and molecular polarizability. The HOMO and LUMO orbitals, also called the frontier orbitals, determine the way the molecule interacts with other species. The HOMO is the orbital that could act as an electron donor, since it is the outermost (highest energy) orbital containing electrons. The LUMO is the orbital that could act as the electron acceptor, since it is the innermost (lowest energy) orbital that has room to accept electrons. According to the frontier molecular orbital theory, the formation of a transition state is due to an interaction between the frontier orbitals (HOMO and LUMO) of reactants [90]. The energy of the HOMO is directly related to the ionization potential and the energy of the LUMO is directly related to the electron affinity. The HOMO-LUMO gap, i.e. the difference in energy between the HOMO and LUMO, is an important stability index [91]. A large HOMO-LUMO gap implies high stability for the molecule in chemical reactions [92]. It is also well established in the literature that the higher the HOMO energy of the inhibitor, the greater the trend of offering electrons to unoccupied d-orbital of the metal, and the higher the corrosion inhibition efficiency [93, 94]. In addition, the lower the LUMO energy, the easier the acceptance of electrons from metal surface, as the LUMO-HOMO energy gap decreased and the efficiency of inhibitor improved. Furthermore, the dipole moment $\mu$ is a measure of the polarity of a covalent bond, which is related to the distribution of electrons in a molecule [95]. Although there are some discrepancies in the literature on the use of $\mu$ as a predictor for the direction of a corrosion inhibition reaction, it is generally agreed that the large values of $\mu$ favor the adsorption of inhibitor onto a metal surface [96]. The polarizability $\langle\alpha\rangle$ is an indicator of the linear response of the electron density in the presence of an infinitesimal electric field, which depends on the second derivative of energy with respect to the electric field. The higher values of $\langle\alpha\rangle$ facilitate the strong adsorption process of corrosion inhibitors onto metallic surfaces and hence, high inhibition efficiency [97].

Recently, more corrosion publications contained substantial quantum chemical calculations and molecular dynamics simulations [98-100]. Such calculations are usually used to explore the relationship between the inhibitor molecular properties and their corrosion inhibition efficiencies. The use of quantum chemical methods in corrosion inhibitor studies of large number of small organic compounds has been highlighted by Gece [88] in his detailed review. Attempt has also been made recently to extend the application of DFT based quantum chemical methods to the assessment of adsorption behavior of polymers as corrosion inhibitors. Awad [101] and Awad et al. [68] has reported on quantum chemical studies and molecular modeling of the effect of polyethylene glycol as corrosion inhibitors of an aluminum surface. It was shown that polyethylene glycol molecules act as good corrosion inhibitors. Quantum chemical simulation showed the effect of molecular weight on the studied polymers with repeating units $1,2,3,4$, and 5 and also polymers with high molecular weights with repeating units 10,20 , and 30 . Using the density functional theory at the B3LYP/6-31G $+(\mathrm{d}, \mathrm{p})$ basis set level, ab initio calculations using the $\mathrm{HF} / 6-31 \mathrm{G}+(\mathrm{d}, \mathrm{p})$ and semi-empirical PM3 methods were performed on polyethylene glycol to investigate the correlation between its molecular structure and the corresponding inhibition efficiency. The calculated parameters include the highest occupied molecular orbital, the lowest unoccupied molecular orbital, the separation energy $(\Delta E)$, the dipole moment $(\mu)$, the softness $(\sigma)$, the fraction of electrons transferred from the inhibitor to the metal surface $(\Delta N)$, the electronegativity $(\chi)$, the hardness $(\eta)$, and the total negative charge. Furthermore, the adsorption energies of the inhibitors with the aluminum (1 1 1) surface were studied using the molecular dynamic simulations approach. A good correlation between the theoretical data and the experimental results was found. The molecular dynamics simulation results showed that all inhibitors could adsorb on the Al surface in the same order as obtained by experimental results. Similarly quantum chemical studies using DFT (density functional theory) at B3LYP/6-31G(d) basis set was performed on the investigation of chitosan as green corrosion inhibitor for copper in acidic medium [27]. Results from the 
computational studies showed that the nitrogen and oxygen atoms in the chitosan molecule are the main active sites that result in adsorption of chitosan on the copper surface resulting in corrosion inhibition effect.

\section{CONCLUSION}

It has been shown that both naturally occurring and synthetic polymers are effective in inhibiting metal corrosion in different aggressive media. Inhibition efficiency has been found to be greatly influenced by the concentration of inhibitor, polymer molecular weight, structure of inhibitor, and temperature. Mechanism of inhibition by polymers is found to be principally due to adsorption through the multiple adsorption sites onto the metal surface. Insolubility of polymer in aqueous solution has been identified as the major factor militating against the use of polymers as metal corrosion inhibitors. However, results of several investigations have shown that modification of polymer composition such as addition of anions to polymer and copolymerization can enhance solubility as well enhance corrosion inhibition efficiency. Quantum chemical calculations and molecular dynamics simulations have also been employed in corrosion inhibition studies using polymers as inhibitors and have been found to provide useful insights into the interactions between the metal substrate and the studied polymers.

\section{CONFLICT OF INTEREST}

The authors confirm that this article content has no conflict of interest.

\section{ACKNOWLEDGEMENTS}

Declared none.

\section{REFERENCES}

[1] Reinhold VN. Corrosion In: Scientific Encyclopedia. Van Nostrand Reinhold International Company Limited, England 1989; $7^{\text {th }}$ ed., vol. 1, pp. 591-659.

[2] Bradford S. Corrosion inhibitors In: S. Bradford. Corrosion Control 2001; 2nd ed., Edmonton, Alberta, Canada: CASTI, pp 345-71

[3] RevieRW. (ed). Uhlig's Corrosion Handbook, $2^{\text {nd }}$ ed. John Wiley \&Sons 2000

[4] Ozdemir D, Cicek V. Aqueous corrosion inhibition studies of mild steel alloy by oxyanion esters of A-hydroxy acids and their salts. Int J Eng Res Appl 2013; 3(1): 969-85.

[5] McCafferty E. Thermodynamic aspects of the crevice corrosion of iron in chromate/chloride solutions. J Electrochem Soc 1979; 126: 385.

[6] McCafferty E. Thermodynamic aspects of the crevice corrosion of iron in chromate/chloride solutions. Corros Sci 1989; 29: 391-401.

[7] U.S. Congress, Office of Technology Assessment, Environmental Policy Tools: A User's Guide, OTA-ENV-634. Washington, DC: U.S. Government Printing Office 1995.

[8] Twite RL, Bierwagen GP. Review of alternatives to chromate for corrosion protection ofaluminum aerospace alloys. Prog Org Coat 1998; 33: 91-100.

[9] Bethencourt M, Botana FJ, Calvino JJ, Marcos M, RodriguezChacon MA. Lanthanide compounds as environmentally-friendly corrosion inhibitors of aluminum alloys: A review. Corr Sci 1998; 40:1803-19.

[10] Toxicological profile for chromium, agency for toxic substance. US Public Health Service, Report no. ATSDR/TP-88/10, 1989

[11] Sanyal B. Organic compounds as corrosion inhibitors in different environments- A review. Prog Org Coating 1981; 9: 165-236.

[12] Abd-El-Maksoud SA. Effect of organic compounds on the electrochemical behavior of steel in acidic media- A review. Int J Electrochem Sci 2008; 3: 528 .
[13] Loto RT, Loto C A, Popoola A P I. Corrosion inhibition of thiourea and thiadiazole derivatives: A review. J Mater Environ Sci 2012; 3 (5): 885-94.

[14] Rajendran S, Sridevi SP, Anthony N, John Amalraji, A, Sundaravadivedi M. Corrosion behavior of carbon steel in polyvinyl alcohol. Anti-Corros Methods Mater 2005; 52: 102-7.

[15] Umoren SA, Solomon MM. Effect of halide ions additives on the corrosion inhibition of aluminium in $\mathrm{HCl}$ by polyacrylamide. The Arab J Sci Eng 2009; 35 (2A): 115-29.

[16] Solomon MM, Umoren SA, Udousoro II, Udoh AP. Inhibitive and adsorption behavior of carboxymethyl cellulose on mild stee corrosion in sulphuric acid solution. Corros Sci 2010; 52: 1317-25.

[17] Umoren SA. Polymers as corrosion inhibitors for metals in different media - A review. Open Corros J 2009; 2: 175-88.

[18] Kalaivani R, ThillaiArasu P, Rajendran S. Corrosion inhibition by polymers - A bird's eyeview. Eur Chem Bull 2013; 2 (10): 807-15.

[19] Gupta RK, Singh RA. Inhibition of corrosion by poly ( $N$ hexadecylaniline)/docosanol mixed Langmuir-Blodgett films on copper in sea water. Mater Chem Phys 2006; 97: 226-9.

[20] Benabdellah M, Ousslim A, Hammouti B, et al. The effect of poly (vinyl caprolactone-co-vinyl pyridine) and poly (vinyl imidazo-covinyl pyridine) on the corrosion of steel in $\mathrm{H}_{3} \mathrm{PO}_{4}$ media. J Appl Electrochem 2007; 37: 819-26.

[21] Jeyaprabha C, Sathiyanarayanan S, Venkatachari G. Co-adsorption effect of polyaniline and halide ions on the corrosion of iron in 0.5 $\mathrm{M} \mathrm{H}_{2} \mathrm{SO}_{4}$ solutions. J Electroanal Chem2005; 583: 232-40.

[22] Umoren SA, Solomon MM, Udousoro II, Udoh AP. Synergistic and antagonistic effects between halide ions and carboxymethyl cellulose for the corrosion inhibition of mild steel in sulphuric acid solutions. Cellulose 2010; 17: 635-48.

[23] Umoren SA, Li Y, Wang FH. Electrochemical study of corrosion inhibition and adsorption behavior for pure iron by polyacrylamide in $\mathrm{H}_{2} \mathrm{SO}_{4}$ : synergistic effect of iodide ions. Corros Sci 2010; 52: 1777-86.

[24] Fares MM, Maayta AK, Al-Qudah MM. Pectin as promising green corrosion inhibitor of aluminum in hydrochloric acid solution. Corros Sci 2012; 60: 112-7.

[25] Hassan RM, Zaafarany IA. Kinetics of corrosion inhibition of aluminum in acidic media by water-soluble natural polymeric pectates as anionic polyelectrolyte inhibitors. Materials 2013; 6: 2436-51.

[26] Umoren SA, Banera MJ, Alonso-Garcia T, Gervasi CA, Mirifico MV. Inhibition of mild steel corrosion in $\mathrm{HCl}$ solution using chitosan. Cellulose 2013; 20: 2529-45.

[27] El-Haddad MN. Chitosan as a green inhibitor for copper corrosion in acidic medium. Int J Biological Macromol 2013; 55: 142-9.

[28] Solmaz R, Altunbas E, Kardas G. Adsorption and corrosion inhibition effect of 2-((5-mercapto-1, 3, 4-thiadiazol-2-ylimino) methyl) phenol Schiff base on mild steel. Mater Chem Phys 2011; 125: 796-801.

[29] Bayol E, Gurten AA, DursunM, Kayakirilmaz K. Adsorption behavior and inhibition corrosion effect of sodium carboxylmethyl cellulose on mild steel in acidic medium. Acta Physco-Chim Sin 2008; 24: 2236.

[30] Arukalam IO, Nleme KI, Anyanwu AE. Comparative inhibitive effect of hydroxyethylcellulose on mild steel and aluminium corrosion in $0.5 \mathrm{M} \mathrm{HCl}$ solution. Academic Res Int 2011; 1(3): 492-8.

[31] Rajeswari V, Kesavan D, Gopiraman M, Viswanathamurthi P. Physicochemical studies of glucose, gellan gum, and hydroxypropyl cellulose - inhibition of cast iron corrosion. Carbohydrate Polym 2013; 95: 288-94.

[32] Bentrah H, Rahali Y, Chala A. Gum Arabic as an eco-friendly inhibitor for API 5L X42 pipeline steel in $\mathrm{HCl}$ medium. Corros Sci 2014; 82: 426-31.

[33] Fekery AM, Mohamed RR. Acetyl thiourea chitosan as an ecofriendly inhibitor for mild steel in sulphuric acid medium. Electrochim Acta 2010; 55: 1933-9.

[34] Li M, Xu J, Li R, et al. Simple preparation of aminothiourea modified chitosan as corrosion inhibitor and heavy metal ion adsorbent. J Coll Interf Sci 2014; 417: 131-6.

[35] Bello M, Ochoa N, Balsamo V, et al. Modified cassava starches as corrosion inhibitors of carbon steel: an electrochemical and morphological approach. Carbohydrate Polym 2010; 82: 561-8. 
[36] Banerjee S, Srivastava V, Singh MM. Chemically modified natural polysaccharide as green corrosion inhibitor for mild steel in acid medium. Corros Sci 2012; 59: 35-41.

[37] Mobin M, Khan MA, Parveen M. Inhibition of mild steel corrosion in acidic medium using starch and surfactants additives. J Appl Polym Sci 2011; 121: 1558-65.

[38] Fares MM, Maayta AK, Al-Mustafa JA. Corrosion inhibition of iota-carrageenan natural polymer on aluminum in presence of zwitterions mediator in $\mathrm{HCl}$ media. Corr Sci 2012; 65: 223-30.

[39] Aly KI, Hussein MA. New polymer synthesis, part 45: corrosion inhibition behavior of novel polyurea derivatives based on diarylidenecycloalkanone moieties in the polymers backbone. J Polym Res 2010; 17: 607-20.

[40] Umoren SA, Gasem ZM. Influence of molecular weight on mild steel corrosion inhibition effect by polyvinyl alcohol in hydrochloric acid solution. J Disper Sci Technol 2013; http://dx.doi.org/10.1080/01932691.2013.833481

[41] Atta AM, El-Azabawy OE, Ismail HS, Hegazy MA. Novel dispersed magnetite core-shell nanogel polymers as corrosion inhibitors for carbon steel in acidic medium. Corros Sci 2011; 53: 1680-9.

[42] Abd El Rehim SS, Sayyah SM, El-Deeb MM, Kamal SM, AzoozRE. Poly (o-phenylenediamine) as an inhibitor of mild steel corrosion in $\mathrm{HCl}$ solution. Mater Chem Phys 2010; 123: 20-7.

[43] Hasanov R, Bilge S, Bilgi S, Gece G, Kilic Z. Experimental and theoretical calculations on corrosion inhibition of steel in $1 \mathrm{M}$ $\mathrm{H}_{2} \mathrm{SO}_{4}$ by crown type polyethers. Corros Sci 2010; 52: 984-90.

[44] Hasanov R, Bilgic S, Gece G. Experimental and theoretical studies on the corrosion properties of some conducting polymer coatings. J Solid State Electro chem 2011; 15: 1063-70.

[45] Hou J, Zhu G, Zheng J. Synthesis, characterization and corrosion protection study of polypyrrole/phosphotungstate coating on low alloy steel in sea water. Polym Sci 2011; 53 (9 - 10): 546-52.

[46] Al Fuhaiman LA, Mustafa AA, Mekhamer WK. Polyvinyl pyrrolidone as a green corrosion inhibitor for carbon steel in alkaline solutions containing $\mathrm{NaCl}$. Anti-Corros Meth Mater 2013; 60(1): 26-8.

[47] Mansri A, Bouras B, Hammouti B, Warad I, Chetouani A. Synergistic effect of AM-4VP-9 copolymer and iodide ion on corrosion inhibition of mild steel in $1 \mathrm{M} \mathrm{H}_{2} \mathrm{SO}_{4}$. Res Chem Intermed 2013; 39: 1753-70.

[48] Ashassi-Sorkhabi H, Es'haghi M. Corrosion protection of mild steel by nano-colloidal polyaniline/nanodiamond composite coating in $\mathrm{NaCl}$ solution. J Coat Technol Res 2013; doi 10.1007/s11998013-9546-7

[49] Ashassi-Sorkhabi H, Es'haghi M. Electro-synthesis of nanocolloidal PANI/ND composite for enhancement of corrosion protection effect of PANI coatings. JMEPEG 2013; 22: 3755-61.

[50] Belkaid S, Tebbji K, Mansri A, Chetouani A, Hammouti B. Poly (4-vinylpyridine-hexadecyl bromide) as corrosion inhibitor for mild steel in acid chloride solution. Res Chem Intermed 2012; 38: 2309-

[51] Karthikaiselvi R, Subhashini S. Study of adsorption properties and inhibition of mild steel corrosion in hydrochloric acid media by water soluble composite poly (vinyl alcohol-o-methoxy aniline). J Assoc Arab Univer Basic Appl Sci 2013; http://dx.doi.org/10. 1016/j.jaubas.2013.06.002

[52] Ali SA, Zaidi SMJ, El-Sharif AMZ, Al-Taq AA. Cyclopolymers from $N, N$-dially- $N$-propargyl-(12-N ${ }^{1}$-formylamino)-1-dodecylammonium chloride and their use as inhibitors for mild steel corrosion. Polym Bull 2012; 69: 491-507.

[53] John S, Kuruvilla M, Joseph A. Surface morphological and impedance spectroscopic studies on the interaction of polyethylene glycol (PEG) and polyvinyl pyrrolidone (PVP) with mild steel in acid solutions. Res Chem Inter med 2013; 39: 1169-82.

[54] Qian B, Wang J, Zheng M, Hou B. Synergistic effect of polyaspartic acid and iodide ion on corrosion inhibition of mild steel in $\mathrm{H}_{2} \mathrm{SO}_{4}$. Corros Sci 2013; 75: 184-92.

[55] Karthikaiselvi R, Subhashini S, Rajalakshmi R. Poly (vinyl alcohol-aniline) water soluble composite as corrosion inhibitor for mild steel in $1 \mathrm{M} \mathrm{HCl}$. Arabian J Chem 2012; 5: 517-22.

[56] Karthikaiselvi R, Subhashini S. The water soluble composite of poly (vinyl pyrrolidone - methylaniline): a new class of corrosion inhibitors of mild steel in hydrochloric acid media. Arabian J Chem 2012; http:/dx.doi.org/10.1016/j.arabjc.2012.10.024
[57] Srimathi M, Rajalakshmi R, Subhashini S. Polyvinyl alcoholsulpanilic acid water soluble composite as corrosion inhibitor for mild steel in hydrochloric acid medium. Arabian J Chem 2010; doi:10.1016/j.arabjc.2010.11.013

[58] Mobin M, Khan AM. Synergistic influence of polyvinyl alcohol and surfactants on the corrosion inhibition of mild steel in $0.1 \mathrm{M}$ $\mathrm{H}_{2} \mathrm{SO}_{4}$. Chem Eng Comm 2013; 200: 1149-69.

[59] Azghandi M V, Davoodi A, Farzi G A, Kosari A. Corrosion inhibitive evaluation of an environmentally friendly water-base acrylic terpolymer on mild steel in hydrochloric acid media. Metallurg Mater Trans A 2013; 44A: 5493-504.

[60] Verma CB, Quraishi MA, Ebenso EE. Electrochemical and thermodynamic investigation of some soluble terpolymers as effective corrosion inhibitors for mild steel in $1 \mathrm{M}$ hydrochloric acid solution. Int J Electrochem Sci 2013; 8: 12894-906.

[61] Barak A, Das PJ, Vashisht H, Kumar S. Synthesis, characterization of water soluble PS-b-PEO-b-PS triblock copolymers and its corrosion inhibition behavior on mild steel in acidic solution. Int $\mathrm{J}$ Sci Res Publications 2014; 4: 2250-3153.

[62] Mobin M, Khan MA. Adsorption and corrosion inhibition behavior of polyethylene glycol and surfactants additives on mild steel in $\mathrm{H}_{2} \mathrm{SO}_{4}$. JMEPEG 2014; 23: 222-9.

[63] Sabirneeza AA, Subhashini S, Rajalakshmi R. Water soluble conducting polymer composite of polyvinyl alcohol and leucine: An effective acid corrosion inhibitor for mild steel. Mater Corros 2013; 64 (1): 74-82.

[64] Subhashini S, Ali A, Sabirneeza, F. Gravimetric and electrochemical investigation of water soluble poly(vinyl alcohol-threonine) as corrosion inhibitor for mild steel. Proceedings of the World Congress on Engineering and Computer Science. Vol II October 19-21, 2011, San Francisco: USA 2001.

[65] Jayalakshmi M, Muralidharan VS. Correlation between structure and inhibition of organic compounds for acid corrosion of transition metals. Ind J Chem Tech 1998; 5 (4): 16-28.

[66] Umoren SA, Li Y, Wang FH. Influence of aluminum microstructure on corrosion and corrosion inhibitor performance in acidic medium. J Mater Environ Sci 2010; 1(3): 189-96.

[67] Abdallah M, Megahed HE, Radwan MA, Abdfattah E. Polyethylene glycol compounds as corrosion inhibitors for aluminum in $0.5 \mathrm{M}$ hydrochloric acid solution. J Am Sci 2012; 8(1): 49-55.

[68] Awad MK, Metwally MS, Soliman SA, El-Zomrawy AA, Bedair MA. Experimental and quantum chemical studies of the effect of polyethylene glycol as corrosion inhibitors of aluminum surface. J Ind Eng Chem 2013; http://dx.doi.org/10.1016/j.jiec.2013.06.009

[69] Zor S, Kandemirli F, Yakar E, Arslan T. Electrochemical synthesis of polypyrrole in aluminum in different anions and corrosion protection of aluminum. Protect Metals Phys Chem Surf 2010; 46(1): 110-6.

[70] Umoren SA, Pan C, Li Y, Wang FH. Elucidation of mechanism of corrosion inhibition by polyacrylic acid and synergistic action with iodide ions by in-situ AFM. J Adhes Sci Technol 2014; 28(1): 317.

[71] El-Deeb MM, Sayyah SM, Abd El-Rehim SS, Mohamed SM. Corrosion inhibition of aluminum with a series of aniline monomeric surfactants and their analog polymers in $0.5 \mathrm{M} \mathrm{HCl}$ solution. Arabian J Chem 2013; http://dx.doi.org/10.1016/j.arabjc. 2013.09.08

[72] Khaled MM. The effect of molecular weight on the corrosion protection properties of polyvinylpyrrolidone polymers on stainless steel. Arab J Sci Eng 2010; 35(1A): 29-39.

[73] Shinde VP, Patil PP. A study on the electrochemical polymerization, characterization, and corrosion protection of $o$-toluidine on steel. J Solid State Electro chem 2013; 17: 29-41.

[74] Oncul A, Coban K, Sezer E, Senkal BF. Inhibition of the corrosion of stainless steel by poly- $N$-vinylimidazole and $N$-vinylimidazole. Progres Org Coat 2011; 71: 167-72.

[75] Doslu ST, Mert BD, Yazici B. Polyindole top coat on $\mathrm{TiO}_{2}$ sol-gel films for corrosion protection of steel. Corros Sci 2013; 66: 51-8.

[76] Leon-Silva U, Nicho ME, Gonzalez-Rodriguez JG, Chacon-Nava JG, Salinas-Bravo VM. Effect of thermal annealing of poly (3octylthiophene) films covered stainless steel on corrosion properties. J Solid State Electro chem 2010; 14: 1089-100.

[77] Zhu G, Hou J, Zhu H, Qiu R, Xu J. Electrochemical synthesis of poly (3, 4-ethylenedioxythiophene) on stainless steel and its 
corrosion inhibition performance. J Coat Technol Res 2013; 10(5): $659-68$.

[78] Govindaraju KM, Gopi D, Basha KA. Synthesis, characterization, and electrochemical evaluation of anti - corrosive performance of poly $\{(N$-methacryloyloxymethyl) benzotriazole-co- $N$-vinylpyrrolidone coatings. J Appl Electro chem 2013; 43: 1043-54.

[79] Flamini DO, Saugo M, Saidman SB. Electrodeposition of polypyrrole on nitinol alloy in the presence of inhibitor ions for corrosion protection. Corros Sci 2014; 81: 36-44.

[80] Huang J, Liu G, Zhou Y, et al. Acrylic acid - allypolyethoxy carbonate copolymer as an environmentally friendly calcium carbonate and iron (III) scale inhibitor. Clean Technol Environ Policy 2013; 15: 677-85.

[81] Pruna A, Pilan L. Electrochemical study on new polymer composite for zinc corrosion protection. Composites: Part B 2012; 43: 3251-7.

[82] Cakmakci I, Duran B, Duran M, Bereket G. Experimental and theoretical studies on anticorrosive properties of poly (pyrrole-co$\mathrm{N}$-methylpyrrole) coatings on copper in chloride media. Corros Sci 2013; 69: 252-61.

[83] Manimaran N, Rajendran S, Manivannan M, John Mary S. Corrosion inhibition of carbon steel by polyacrylamide. Res J Chem Sci 2012; 2(3): 52-7.

[84] Omrani A, Ali rostami A, Sharifirad M. Synthesize, characterization, and corrosion inhibition of polypyrrole thin films on copper. J Macromolecul Sci, Part A: Pure and Appl Chem 2013; 50: 513-21.

[85] Khairou KS, El-Sayed A. Inhibition effect of some polymers on the corrosion of cadmium in a hydrochloric acid solution. J Appl Polym Sci 2003; 88: 866-71.

[86] Gece G, Bilgic S. Quantum chemical study of some cyclic nitrogen compounds as corrosion inhibitors of steel in $\mathrm{NaCl}$ media. Corros Sci 2009; 51: 1876-8.

[87] Kraka E, CremerD, Computer design of anticancer drugs. J Am Chem Soc 2000; 122: 8245-64.

[88] Gece K, The use of quantum chemical methods in corrosion inhibitor studies. Corros Sci 2008;50: 2981-2992.

[89] Obot IB, Recent advances in computational design of organic materials for corrosion protection of steel in aqueous media, In:
Aliofkhazraei M (ed) "Developments in Corrosion Protection", INTECH, Croatia, 2014; pp 123-51.

[90] Fukui K. Theory of Orientation and Stereoselection, SpringerVerlag: New York 1975.

[91] Lewis DFV, Ioannides C, Parke DV, Interaction of a series of nitriles with the alcohol-inducible isoform of P450: computer analysis of structure-activity relationships. Xenobiotica1994; 24: 401-8.

[92] Zhou Z, Parr RG, Activation hardness: new index for describing the orientation of electrophilic aromatic substitution. J Am Chem Soc 1990; 112: 5720-4.

[93] Obot IB, Obi-Egbedi NO, Adsorption properties and inhibition of mild steel in sulphuricacid solution by ketoconazole: experimental and theoretical investigation. Corros Sci 2010; 52: 198-204.

[94] Obot IB, Obi-Egbedi NO, Umoren SA, The synergistic inhibitive effect and some quantum chemical parameters of 2,3diaminonapthalene and iodide ions on the hydrochloric acid corrosion of aluminium. Corros Sci 2009; 51:276-82.

[95] Li X, Deng S, FuH, Li T, Adsorption and inhibition effect of 6benzylaminopurine on cold rolled steel in $1.0 \mathrm{M} \mathrm{HCl}$. Electrochim Acta 2009; 54: 4089-98

[96] Kandemirli F, Sagdinc S, Theoretical study of corrosion inhibition of amides and thiosemicarbazones. Corros Sci 2007; 49: 2118-30.

[97] Awad MK, Mustafa MR, Abo Elnga MM. Computational simulation of the molecular structure of some triazole as inhibitors for the corrosion of metal surface. J Mol Struct 2010; 959: 66-74.

[98] Hegazy MA, Badawi AM, Abd El Rehim SS, Kamel WM. Corrosion inhibition of carbon steel using novel N-(2-(2-mercaptoacetoxy)ethyl)- N,N-dimethyl dodecan-1-aminium bromide during acid pickling. Corros Sci 2013; 69: 110-22.

[99] Obi-Egbedi NO, Obot IB. Inhibitive properties, thermodynamic and quantum chemical studies of alloxazine on mild steel corrosion in $\mathrm{H}_{2} \mathrm{SO}_{4}$. Corros Sci 2011; 53: 263-75.

[100] Zhang J, Qiao G, Hu S, Yan Y, Ren Z, Yu L. Theoretical evaluation of corrosion inhibition performance of imidazoline compounds with different hydrophilic groups. Corros Sci 2011; 53: 147-52.

[101] Awad MK. Quantum chemical studies and molecular modeling of the effect of polyethylene glycol as corrosion inhibitors of an aluminum surface. Can J Chem 2013; 91(4): 283-91. 